\title{
Revisión sobre la alelopatía de Eucalyptus l'Herit
}

\author{
Francisco J. Espinosa-García \\ Centro de Ecología, Departamento de Ecología Evolutiva, Universidad Nacional Autónoma de México, \\ Apdo. postal 70-275, 04510, México, D.F., México.
}

\begin{abstract}
Resumen. Algunas especies de eucalipto pueden ser asociadas con la producción de zonas de inhibición alrededor o bajo los árboles donde la vegetación es menos diversa, menos vigorosa y/o menos densa que las zonas lejanas a los eucaliptos. La cercanía de eucaliptos a algunos cultivos produce bajos rendimientos y/o crecimiento pobre en las plantas cultivadas. Aunque la competencia por agua y nutrientes puede explicar algunos casos, ésta es insuficiente para explicar otros. La evidencia de campo sugiere que en varios casos la alelopatía puede explicar, al menos parcialmente, la existencia de zonas de inhibición. Los efectos alelopáticos no ocurren cuando los aleloquímicos no se acumulan en el suelo debido a sus características edáficas o al régimen de lluvias ni cuando las especies blanco no son afectadas por los aleloquímicos. Las hojas y cortezas de los eucaliptos contienen numerosos ácidos fenólicos, flavonoides, taninos y monoterpenoides que son fitotóxicos in vitro. Los extractos o lixiviados de hojas, corteza, hojarasca y semillas de varias especies de eucalipto contienen aleloquímicos capaces de afectar negativamente a varias especies de plantas. Estas sustancias han sido detectadas en agua y suelo donde se han disuelto o acumulado naturalmente en concentraciones suficientes para producir efectos alelopáticos. Los aleloquímicos se pueden liberar naturalmente de todo tipo de tejidos, vivos o muertos, aunque la fitotoxicidad varía de acuerdo con la especie de eucalipto. Las distintas partes de los eucaliptos tienen diferente capacidad para liberar sustancias alelopáticas. En general, cualquier parte molida o pulverizada liberará más metabolitos secundarios que en forma entera. Aunque ningún trabajo publicado reúne irrefutablemente todos los tipos de evidencia necesaria para demostrar alelopatía de eucaliptos, el conjunto de evidencia sugiere que los efectos alelopáticos de varios eucaliptos en condiciones naturales existen.
\end{abstract}

Palabras clave: aleopatía, Eucalyptus, liberación y acumulación de aleoquímicos.

Abstract. Some eucalyptus species can be associated to the production of zones where vegetation is absent, sparse and/or less diverse and vigorous than surroundig zones away from eucalypts. These zones have been documented with eucalypts growing as native or introduced species. Yield reduction and poor plant performance is frequent when some crops, annual or perennial, are planted within or around eucalipt stands. Although competition for water, light and nutrients can explain some of these inhibition patterns, it is insufficient to explain others. Field evidence suggets that allelopathy explains, at least partially, the aforementioned inhibition areas. Inhibition zones are absent where the soil does not accumulate allelochemicals and the watering or rainy regime leaches them out, or the plants surronding eucalypts are unaffected by the chemicals. Phenolic acids, tannins, flavonoids and/or terpenoids have been isolated from eucalypt bark, litter and leaves; leachates or extracts from these parts have been shown to be phytotoxic in vitro and in greenhouse experiments for most target species tested. Allelochemicals are naturally released, from intact, dead or alive, eucalypt tissues and accumulated in water or soil in concentrations high enough to produce allelopathic effects. Milled or chopped eucalypt parts release more allelochemicals and faster than intact parts. Although no published work contains all the undisputed evidence required to demonstrate eucalypts' allelopathy, the body of evidence in the published works suggets that some eucalypt species do produce allelopathic effects in natural conditions.

Key words: allelopathy, Eucalyptus, release and accumulation of allelochemicals.

as especies del género Eucalyptus tienen reputación de alelopáticas. Esto es, que son capaces de producir y liberar sustancias que inhiben el desempeño de otras plantas en condiciones silvestres o de cultivo. Desde que Story (1967, en Poore y Fries, 1985) y después del Moral y Müller $(1969,1970)$ notificaron 
efectos alelopáticos de varias especies de Eucalyptus, se han publicado numerosos informes sobre alelopatía, muchas veces con resultados contradictorios. En algunos casos la alelopatía de los eucaliptos ha sido declarada de poca importancia (Lima, 1987; Shrivastava y Lal, 1989; Sanginga y Swift, 1992) y en otros casos se ha satanizado a este árbol por sus supuestos efectos sobre otras especies, incluido el alelopático (p. ej. Kholi, 1987, en Singh y Kholi, 1992). En varios sistemas agroforestales se han encontrado efectos nocivos sobre cultivos asociados, atribuidos al eucalipto (Poore y Fries, 1985). En algunos de estos casos el efecto nocivo se ha atribuido a competencia directa por luz, agua y/o nutrientes, mientras que en algunos otros se ha señalado a la alelopatía como responsable. Sin embargo, son pocos los casos donde se demuestra concluyentemente si la competencia o la alelopatía o una combinación de ambas causaron los efectos nocivos.

Las especies de Eucalyptus son alrededor de 500 y se originaron principalmente en Australia y en pocos casos en Nueva Zelanda, Tasmania Indonesia y Nueva Guinea (Pryor, 1976). Cerca de 35 de estas especies son cultivadas extensivamente en el mundo para obtener celulosa y leña, para reforestar y como rompevientos (Pryor, 1976). La gran productividad de los eucaliptos en plantaciones y su uso en reforestación hacen que la expansión del cultivo de estos árboles sea atractiva. Puesto que los efectos alelopáticos potenciales serían importantes en la evaluación del impacto ecológico del eucalipto, es necesario determinar si estos efectos existen, y si es así, encontrar cuál es su magnitud.

El objetivo de esta revisión es evaluar si existen efectos alelopáticos producidos por Eucalyptus spp., y en caso de que existan, encontrar en qué condiciones ocurren; cuáles especies son afectadas y si hay medidas de manejo que puedan mitigar o anular los efectos alelopáticos.

Esta revisión no pretende ser exhaustiva, pues se han publicado numerosos artículos sobre alelopatía y eucaliptos, en la India, Pakistán y otros países, que no están disponibles en México. A pesar de que no obtuve todos los artículos o resúmenes, considero que lo que se expone a continuación representa bien los principales avances en el conocimiento sobre alelopatía y eucalipto. Algunas de las publicaciones que no estuvieron disponibles fueron consultadas en forma de resumen.

La demostración de efectos alelopáticos requiere evidencia de varios tipos: a) demostración de efectos adversos de la planta supuestamente alelopática sobre otras plantas, $b$ ) que la planta supuestamente alelopática tenga sustancias químicas (aleloquímicos) capaces de interferir negativamente con el crecimiento y desarrollo de otras plantas, $c$ ) que estos aleloquímicos se liberen en forma natural o como consecuencia del manejo de la planta en el campo, y $d$ ) que los aleloquímicos se liberen o se acumulen en el ambiente en concentraciones suficientes para causar efectos negativos en plantas con las que la planta fuente convive o puede convivir. La revisión de evidencia sobre alelopatía de eucaliptos en este trabajo está organizada de acuerdo a los incisos anteriores, a los que les sigue una discusión general. En el cuadro 1 se reseñan la mayoría de los trabajos de alelopatía de eucaliptos considerados en el trabajo; contiene los nombres de las especies de que han sido expuestas a la acción de los eucaliptos o sus partes.

\section{Evidencia de campo de efectos adversos de los eucaliptos sobre otras plantas.}

La presencia de algunas especies de eucalipto frecuentemente está asociada con zonas alrededor o bajo los árboles donde la vegetación es menos diversa, menos vigorosa y/o menos densa que las zonas lejanas a los eucaliptos. Esto puede ocurrir cuando los eucaliptos son nativos o introducidos y con plantas cultivadas o silvestres. La evidencia que apoya estas afirmaciones se presenta a continuación.

\section{Efectos nocivos de eucaliptos nativos en condiciones silvestres.}

En chaparrales costeros australianos donde hay Eucalyptus baxteri, varias especies simpátricas no crecen bajo la copa de este eucalipto aunque crecen frecuentemente bajo la copa de otras especies de arbustos vecinos (Del Moral et al., 1978). En este caso, además de confirmar cuantitativamente la incidencia diferencial de especies bajo la copa del eucalipto, no hubo diferencias en el contenido de humedad y la cantidad de iluminación y nutrientes bajo la copa de E. baxteri y de otras especies de chaparral. Tampoco observaron indicios de que hubiera actividad animal diferente entre las especies de arbustos. Los autores también mostraron con bioensayos que los lixiviados o extractos de hojas de este eucalipto inhibieron la germinación de las especies que no crecían bajo E. baxteri.

En los bosques australianos de E. regnans $\mathrm{F}$. Muell. (Ashton y Willis, 1982) y de E. delegatensis R.T. Baker (Bowman y Kirkpatrick, 1986) no hay regeneración natural de estas especies pues sus plántulas no sobreviven bajo las copas de estos árboles. En ambos casos se exploraron explicaciones adicionales a la alelopatía. Para E. regnans se encontró que la competencia por agua no fue importante, pero los pató- 
genos podían explicar en parte la mortalidad de las plántulas. Sin embargo, encontraron que los exudados de raíces vivas de árboles adultos y el suelo cercano a los troncos de estẹ eucalipto causaron achaparramiento severo de las plántulas. En el caso de E. delegatensis se encontró que la alelopatía explicaba muy poco la inhibición del crecimiento de las plántulas, pero que la competencia por agua explicaba su baja sobrevivencia y su pobre desempeño.

\section{Efectos nocivos de eucaliptos introducidos sobre plantas silvestres.}

Poore y Fries (1985) concluyeron en su revisión que las plantaciones de eucalipto, así como de otros árboles introducidos, causaban disminución de diversidad en la flora del sotobosque cuando se comparaban con plantaciones de árboles nativos. Evidencia más reciente indica que ciertas especies de eucalipto pueden reducir la diversidad y/o producción de biomasa de la flora de su sotobosque más que otras especies introducidas. Suresh y Rai (1988) compararon la productividad y diversidad del sotobosque de plantaciones de especies introducidas en India (Leucaena leucocephala (Lam.) de Wit., Casuarina equisetifolia Forst. \& Forst. y Eucalyptus tereticornis Smith). Encontraron que el sotobosque de L. leucocephala tuvo menos especies que el de eucalipto y éste, a su vez, menos que el de casuarina. Sin embargo, la biomasa de la flora del sotobosque del eucalipto fue menor que las de las otras dos floras. Los autores atribuyeron estos efectos a aleloquímicos, pues no encontraron diferencias en nutrientes y humedad en los suelos de las plantaciones y de sitios abiertos. Así mismo, la cantidad de luz que alcanzaba al sotobosque era igual entre las plantaciones. Otros autores también han atribuido la baja densidad y diversidad de la vegetación de sotobosque de plantaciones de eucalipto a alelopatía (AlMousawi y Naib 1975, en Singh y Kohli, 1992).

En California, Del Moral y Müller $(1969,1970)$ realizaron trabajos intensivos probando la hipótesis del efecto alelopático de Eucalyptus camaldulensis Dehnh. sobre especies anuales de pastizales adyacentes a los eucaliptos. Además de observar zonas desnudas de vegetación cerca de los árboles, también documentaron gradientes de escasez-abundancia e incremento de biomasa en la vegetación a medida que se incrementaba su lejanía de los troncos del eucalipto. Además de que constataron que no hubo diferencias en humedad o nutrientes en el suelo del gradiente mostraron con bioensayos que los lixiviados de las hojas y hojarasca eran inhibidores de la germinación y crecimiento de muchas de las plantas de los pastizales vecinos. Sin embargo, también encontraron que las zonas de inhibición estaban ausentes cuando $E$. camaldulensis crecía en suelos arenosos.

\section{Efectos nocivos de eucaliptos introducidos sobre cultivos en el campo.}

a] Cultivos perennes. El rendimiento de la yuca ( $\mathrm{Ma}$ nihot esculenta L.) se redujo cuando se cultivó junto con Eucalyptus tereticornis (Gosh et al., 1989), y con un eucalipto híbrido (Gosh et al., 1987). En ambos casos se atribuyó la disminución en rendimiento al sombreado y a la competencia por agua y nutrientes, aunque no se excluyó experimentalmente la alelopatía. En cultivos de mandarina coorg (Citrus reticulata Blanco) con Casuarina equisetifolia, Grevillea robusta A. Cunn. y Eucalyptus sp. el rendimiento del cítrico con Casuarina equisetifolia fue ligeramente mayor que en monocultivo y ligeramente menor que las que crecían con Grevillea robusta. El rendimiento de la mandarina plantada con el eucalipto fue el más bajo (Allolli et al., 1988). Estos autores encontraron poca humedad y carbón orgánico en el suelo bajo los eucaliptos, en comparación con el suelo que estaba bajo otros árboles, por lo que sugirieron que ésto fue la causa del bajo rendimiento de la mandarina. Un caso similar es el del mango (Mangifera indica L.) cuando crece cerca de vallas rompevientos de eucalipto en India. El crecimiento, altura, diámetro y rendimiento de los árboles de mango es menor que cuando hay cultivo monoespecífico o crece cerca de Leucaena leucocephala (Kamal-Sharma et al. 1995).

Todos los trabajos de esta sección no fueron diseñados para probar alelopatía, aunque muy posiblemente los eucaliptos resultan más competitivos que estos cultivos perennes y esto causa los efectos nocivos observados.

b] Cultizos anuales. La aplicación de hojarasca de eucalipto sobre cultivos (un experimento clásico para los que buscan probar alelopatía) no necesariamente resulta en efectos nocivos para los cultivos. Por ejemplo, Tomar et al. (1992) aplicaron 4 ton/ha de hojas secas de un eucalipto híbrido (posiblemente de Eucalyptus tereticornis), en surcos y después de la siembra, a cultivos de trigo y maíz. Los rendimientos fueron iguales o mayores que los obtenidos en suelo sin hojas de eucalipto. Más aún, estos rendimientos fueron similares a los obtenidos con cantidades similares de hojarasca de especies de otros géneros de árboles.

$\mathrm{Al}$ igual que con cultivos perennes, se ha mostrado que algunos eucaliptos son más eficientes que otras especies de árboles compitiendo con cultivos anuales; por ejemplo, el rendimiento de maíz, sorgo y garbanzo se ve reducido si se cultivan entre Casuarina equisetifolia, Leucaena leucocephala y Eucalyptus tere- 
ticornis. Sin embargo, la reducción de rendimiento es mayor bajo la influencia de E. tereticornis (Rai y Suresh, 1988).

A diferencia se los experimentos anteriores, los hechos con cultivos anuales plantados en gradientes de distancia a eucaliptos, sugieren que la alelopatía ocurre en condiciones de campo. En general, se ha observado que las plantas cercanas a eucaliptos rinden menos y son de talla menor que las plantas lejanas a estos árboles. En los estudios reseñados a continuación se fertilizó o se cuidó que no hubiera diferencias en el contenido de humedad, nutrientes o iluminación (por ejemplo, sembrar donde no se proyecta sombra) en los gradientes de distancia con respecto a los eucaliptos. Basu et al. (1987) observaron papa y trigo cultivados en un gradiente de distancias perpendicular que se alejaba de una valla de Eucalyptus tereticornis y de papa en un gradiente similar respecio a una valla del árbol Glyricidia sp. A pesar de que no hubo diferencias en nutrientes, agua (había un canal entre los troncos de los árboles y los cultivos) o iluminación a lo largo del gradiente, las plantas que crecieron a $3.8 \mathrm{~m}$ de los eucaliptos produjeron $67 \%$ menos kilogramos de papa que las plantas que crecieron a $19.8 \mathrm{~m}$. Las plantas que crecieron a $11.8 \mathrm{~m}$ de los eucaliptos produjeron $48.3 \%$ menos que las plantas crecidas a $20 \mathrm{~m}$ o más. El tamaño de las papas fue pequeño cerca de los eucaliptos y grande lejos de ellos. Las papas cercanas a Glyricidia sp. no sufrieron reducción en rendimiento ni en tamaño. En el trigo también se observaron reducciones en crecimiento que eran más fuertes mientras más cercano estaba el eucalipto. Igboanugo (1988) obtuvo resultados similares cuando sembró chile (Capsicum annum L.) en un gradiente de distancia de una plantación de Eucalyptus citridora Hook. f. y en otro gradiente de distancia con Acais auriculiformis A. Cunn. $\mathrm{El}$ autor encontró que no hubo diferencias en forma o rendimiento del chile en el gradiente de distancia de la acacia, pero en el gradiente con eucalipto encontró reducción en rendimiento y en tamaño de frutos del chile. La inhibición fue total a $1 \mathrm{~m}$ de distancia del eucalipto, aunque ésta disminuyó gradualmente hasta desaparecer después de $5 \mathrm{~m}$ de distancia de los árboles. Kohli et al. (1990) encontraron patrones similares en tres localidades distantes entre sí. Cuando varios cultivos anuales se plantaron a varias distancias de E. tereticornis los efectos nocivos desaparecían a los $11 \mathrm{~m}$ de distancia de los árboles. Singh y Kohli (1992) encontraron que la distancia a la que desaparecía la inhibición alelopática de E. tereticornis fue variable según el cultivo con el que se experimentó. Con Lens esculentum $\mathrm{L}$ la inhibición desapareció a $\operatorname{los} 12 \mathrm{~m}$ de distancia del eucalipto, mientras que con Triticum aestizum L., Trifolium alexandrinum L., Brassica oleracea L. y Cicer arietinum L. desapareció a los 9 m. Estos investigadores también extrajeron las fitotoxinas delsuelo originadas por el eucalipto a diferentes distancias de los árboles. La concentración de compuestos extraídos del suelo superficial $(0-5 \mathrm{~cm})$ fue máxima a $1 \mathrm{~m}$ del árbol: $5 \mathrm{mg} / \mathrm{g}$ de suelo contra $1.8 \mathrm{mg} / \mathrm{g}$ de suelo sin eucalipto. La concentración de fitotoxinas fue de menos de $1.5 \mathrm{mg} / \mathrm{g}$ cuando el suelo fue extraído de profundidades de entre 30 y $65 \mathrm{~cm}$ sin importar la presencia de eucalipto. Las fitotoxinas extraídas inhibieron, en bioensayos, la germinación y crecimiento de Lens esculentum a partir de concentraciones de 0.05 por ciento.

Aunque en los experimentos que se acaban de reseñar se cuidó que no hubiera diferencias iniciales de nutrientes en el suelo, en ninguno se midió la cantidad de nutrientes disponibles al final del experimento. Esto podría indicar que los efectos observados podrían deberse a competencia antes que a alelopatía, si los niveles de nutrientes al final no fueran iguales en las parcelas experimentales (cf. Harper, 1977). Para el caso de Singh y Kohli (1992), la hipótesis de efectos alelopáticos es sólida, pues extrajeron las toxinas del suelo y con ellas indujeron efectos nocivos sobre una de sus especies experimentales simulando las concentraciones de toxinas del suelo.

Aunque en casi todos los experimentos anteriores se irrigó para aliviar la posible competencia por agua de los eucaliptos, no se excluye completamente la posibilidad de alguna competencia, pues los eucaliptos pudieron haber incrementado su demanda de agua con el riego. Eucalyptus camaldulensis y E. tereticornis tienen la mayoría de sus raíces distribuidas uniformemente en los $100 \mathrm{~cm}$ superficiales de limos arenosos, mientras que el maíz las distribuye en los primeros $50 \mathrm{~cm}$ (Jonsson et al., 1988). Una exclusión completa de la posibilidad de competencia por agua puede lograrse mediante la excavación de trincheras que corten las raíces de los eucaliptos. Onyewotu et al. (1994) realizaron un experimento de este tipo con mijo (Pennisetum typhoides [muy posiblemente P. glaucum (L.) R.Br.] plantado en un gradiente de distancia con Eucalyptus camaldulensis), y mostraron que la presencia de trincheras eliminaba la reducción de rendimiento del mijo en las cercanías del árbol. Este experimento excluye la posibilidad de competencia por agua, pero no excluye la posibilidad de que las raíces vivas del eucalipto pudieran haber exudado aleloquímicos y contribuido a la inhibición del mijo. En contraste, las observaciones de Basu el al. (1987) sugieren efectos alelopáticos, pues los cultivos estaban separados de los árboles por un canal de $50 \mathrm{~cm}$ de profundidad. 
También se han atribuido efectos alelopáticos indirectos de los eucaliptos sobre cultivos que no forman micorrizas por la supuesta acción de los aleloquímicos. Cultivos de leguminosas (Cajanus sp.) y girasol (Helianthus annus L.) plantados entre dos hileras monoespecíficas de árboles separadas entre sí por $35 \mathrm{~m}$ (Dendrocalamus strictus Nees., Tectona grandis L., Leucaena leucocephala, Casuarina equisetifolia, Dalbergia sissoo Roxb. y Eucalyptus tereticornis) ejemplifican este efecto indirecto (Rajashekhara et al., 1989). Se encontró en todos los casos, excepto con eucalipto, que la incidencia de micorrizas vesículo-arbusculares en los cultivos crecía a medida que la distancia al tronco de los árboles aumentaba. En la zonas flanqueadas por eucalipto las micorrizas fueron inhibidas totalmente. El resultado de este experimento es sugestivo para el caso de alelopatía, aunque faltaría excluir la posibilidad de que el estress hídrico en los cultivos por competencia impidiera la micorrización.

Resumiendo esta sección, la evidencia de campo muestra que la hipótesis de alelopatía de algunas especies de eucalipto se apoya o es muy plausible contra varias especies nativas o introducidas que pueden ser cultivadas o silvestres. Además, se muestra que los efectos alelopáticos no ocurren en ciertos tipos de suelos y que la presencia de eucaliptos o de sus partes no afecta negativamente a varias especies de plantas. También es aparente que los eucaliptos son competidores más eficientes que otras especies arbóreas y cultivos y que en muchos, pero no todos los casos, esta habilidad competitiva parece explicar mejor los efectos nocivos de los eucaliptos sobre algunas plantas.

\section{Incidencia de aleloquímicos en especies de eucaliptos deletéreos para otras plantas}

Los eucaliptos, como todas las plantas, tienen varios tipos de aleloquímicos que pueden funcionar como antagonistas de herbívoros y fitopatógenos o alelopáticos. Las hojas y cortezas de los eucaliptos contienen numerosos ácidos fenólicos, flavonoides y taninos (Hillis, 1966, 1967; Okamura et al., 1993 Souto et al., 1994, 1995). Las hojas también contienen muchos monoterpenoides (principalmente cineol, limoneno, pinenos y felandrenos) (Del Moral y Müller, 1966; Nishimura et al., 1984; Barton et al., 1989) y otros floroglucinoles de mono o sesquiterpenos (Kokumai et al., 1991). Muchas de estas sustancias, particularmente ácidos fenólicos y algunos monoterpenos han mostrado ser tóxicas in vitro contra varias especies de plantas (Singh et al., 1991; Souto et al., 1995).

Numerosos bioensayos muestran que extractos o lixiviados de hojas, corteza, hojarasca y semillas de varias especies de eucalipto contienen aleloquímicos capaces de afectar negativamente a varias especies de plantas (cuadro 1). La conclusión abrumadora de estos estudios es que todas las especies de eucalipto probadas tienen sustancias que inhiben, en diferentes grados, el crecimiento y la germinación de muchas, pero no todas, las plantas expuestas in vitro o en invernadero a los extractos o lixiviados. En general, la inhibición se incrementa con la concentración de las sustancias obtenidas de las partes del eucalipto (p. ej. May y Ash, 1990; Kholi y Singh, 1991; Sanginga y Swift, 1992; Lisanework y Michelsen, 1993). La concentración de estas sustancias en los medios usados en los bioensayos se incrementa cuando el material fuente es molido o fragmentado. Además, hay susceptibilidad diferencial a las sustancias dependiendo de la especie de cultivo probada (Tomar et al., 1992; Lisanework y Michelsen, 1993).

El uso de varios de estos estudios para concluir alelopatía es criticable pues la extrapolación de estos resultados a las condiciones naturales resulta difícil. Por un lado, muchos aleloquímicos son fitotóxicos y su sola presencia no es prueba de interacciones alelopáticas (Harper, 1977). Lo importante es que estos metabolitos deben liberarse y permanecer en el ambiente en concentraciones suficientes para producir inhibición en otras plantas. Muchos metabolitos secundarios son inestables o son adsorbidos por partículas de suelo o se difunden rápidamente con aire o agua y no necesariamente alcanzan concentraciones suficientes para tener efecto alelopático (Molina et al., 1991). Por otro lado, en muchas ocasiones las técnicas usadas para extraer las presuntas sustancias alelopáticas no reflejan lo que ocurre en condiciones naturales y elevan artificialmente las concentraciones de las sustancias inhibidoras (May y Ash, 1990).

Liberación y acumulación naturales de aleloquímicos de eucaliptos en el ambiente

Los aleloquímicos de varias especies de eucaliptos han sido detectados y cuantificados en agua y suelo donde se han disuelto o acumulado naturalmente. De suelo cercano a eucaliptos se han detectado terpenoides, ácidos fenólicos y taninos en concentraciones suficientes para producir efectos alelopáticos (Del Moral y Müller, 1969, 1970; Nishimura et al., 1984; Singh y Kohli, 1992). Lo mismo ha ocurrido con el agua de lluvia que ha lavado el follaje de eucaliptos o agua condensada en hojas expuestas a niebla con ácidos fenólicos y taninos (Del Moral y Müller, 1969).

Los trabajos donde se adiciona hojarasca u hojas a macetas también pueda dar evidencia de liberación de aleloquímicos siempre y cuando se controlen los 
problemas de inmovilización de nitrógeno en el suelo y el cambio de textura edáfica. Cuando se agrega una fuente de materia orgánica pobre en nitrógeno, como lo son las hojas u hojarasca de eucalipto, y el suelo no es rico en este nutriente, se provoca un cambio en el balance Carbono/Nutrientes $(\mathrm{C} / \mathrm{N})$ en el suelo. El exceso de materia orgánica promueve el crecimiento de microbios edáficos que usan rápidamente el nitrógeno disponible en el suelo, por lo que se causan problemas de fertilidad para las plantas. Por ejemplo, la adición de hojarasca de Eucalyptus grandis W.Hill ex Maiden a macetas con suelo donde se sembró maíz provocó una dismịnución significativa de $68 \%$ en el peso de la parte aérea del maíz con respecto al sembrado en un suelo sin hojarasca en el primer año de cultivo. Esto podría haberse tomado como evidencia de alelopatía, sin embargo, en el segundo ciclo de cultivo donde no hubo adición nueva de hojarasca, el efecto se revirtió. El suelo que había recibido hojarasca en el primer ciclo produjo maíz $97 \%$ más pesado que el control en el segundo ciclo de cultivo (Sanginga y Zwift, 1992). Los autores interpretaron la inhibición en el primer año como resultado de la alteración en el balance $\mathrm{C} / \mathrm{N}$ que produjo la inmovilización de los nutrientes. El incremento en el rendimiento se atribuyó a la liberación de los nutrientes que había en el suelo y a los que aportó la hojarasca del eucalipto después de que fue consumida por los microbios del suelo. Aunque esta explicación es muy factible, no excluye la posibilidad de que hubiera un efecto alelopático actuando en combinación con la inmovilización de nutrientes y de que las sustancias inhibidoras hubieran desaparecido en el segundo año.

Paulino et al. (1987) añadieron follaje y raíces de Eucalyptus sp. de Brasil a macetas con un latosol donde había crecido eucalipto y a otras con un podsol sin historial de eucalipto. En ambos casos hubo macetas testigo sin partes de eucalipto. Fertilizaron los suelos y después sembraron varias especies de leguminosas y un pasto forrajero. Encontraron que, donde se añadió follaje o raíces de eucalipto, el rendimiento, nodulación y crecimiento de las leguminosas fue significativamente menor en el suelo donde había crecido eucalipto. Sin embargo, el suelo sin historial de eucalipto añadido con follaje y raíces produjo leguminosas con rendimientos similares al de los suelos sin añadidos. Esto sucedió sin importar si los suelos tenían o no historial de cultivo de eucalipto. Estos investigadores encontraron que la leguminosa más sensible fue la soya perenne (Glycine wigtii Verdc.) comparada con Desmodium inornatum (Mill.) Urb. y Galactia striata (Jacq.) Urb. También encontraron que el pasto forrajero Panicum maximum Jacq. no sufrió ningún efecto adverso por la adición de partes de eucalipto en ninguno de los dos tipos de suelo. Este estudio sugiere que hubo efectos alelopáticos del follaje y raíces de eucalipto sobre las especies de leguminosas. Una explicación de esto es que el suelo donde creció eucalipto acumuló toxinas y el material de eucalipto liberó sustancias que actuaron conjuntamente con las del suelo. Otra es que el material de eucalipto liberó sustancias alelopáticas en concentraciones altas que fueron anuladas por el suelo donde no había crecido eucalipto mientras que en el otro suelo no ocurrió así. En un experimento similar en la India se reporta que el girasol, sorgo y lenteja son inhibidos en su germinación y crecimiento por suelo superficial de plantación de Eucalyptus sp. y por la hojarasca de esta especie (Suresh y Rai, 1987)

\section{Liberación de aleloquímicos por eucaliptos o sus partes}

Los estudios de May y Ash (1990) y de Molina et al. (1991) son los que ilustran mejor la liberación natural de aleloquímicos de tejidos de eucalipto vivos o muertos y la dinámica de liberación el tiempo de algunos de estos tejidos. May y Ash (1990) usaron técnicas que simulaban la caída diaria de lluvia sobre hojarasca, hojas del dosel y escurrimientos del tallo de varias especies de eucalipto en Australia. También colectaron exudados radiculares en cultivos hidropónicos de E. globulus Labill. y además suelo superficial de lugares con y sin eucaliptos. Encontraron que los escurrimientos de tallo de E. rossii R.T. Bak. \& H.G. Sm., E. globulus y E. macrorhyncha F. Muell. ex Benth. inhibieron al menos en $50 \%$ la geminación de Lolium perenne L. y el crecimiento de Lemna minor L. En cambio, los lixiviados de hojarasca fresca y de corteza en concentraciones naturales no inhibieron a estas especies en el laboratorio, excepto la hojarasca de $E$. macrorhyncha y los lixiviados de corteza de E. rossii, que inhibieron el crecimiento de Lemna minor. Los lixiviados de hoja y corteza de E. rubida Deanne \& Maid inhibieron el crecimiento de E. globulus, Lolium perenne y Acacia saligna (Labill.) H. Wendl. en macetas cuando fueron aplicados simulando eventos de lluvia. En cuanto a los suelos, encontraron que donde había crecido eucalipto, el suelo no inhibió diferencialmente la germinación de $L$. perenne comparado con suelo de pastizal. Sin embargo, sí encontraron que cuando cualquiera de estos suelos era regado con lixiviados de hojas y corteza, la germinación de esta especie era afectada. Además, encontraron que el efecto se hacía más pronunciado a medida que el suelo se regaba así durante más tiempo. Ellos duplicaron este efecto concentrando grandes volúmenes de lixiviado y virtiéndolo al suelo. Los exudados de raíces en cultivo 
hidropónico de E. globulus resultaron muy poco activos; esto contrasta con la inhibición por raíces vivas producida por E. regnans sobre sus propias plántulas donde no había competencia entre el árbol y la plántula (Ashton y Willis, 1982).

Molina et al. (1991) colectaron lixiviados de hojarasca, follaje en pie y escurrimientos de tronco en una plantación de 23 años de E. globulus durante 5 meses. También colectaron suelo superficial de la plantación durante el mismo tiempo. Para saber si estos materiales derivados de la plantación de eucalipto producían aleloquímicos usaron semillas de lechuga como bioindicador. Encontraron que, en general, ni los lixiviados del follaje en pie ni los escurrimientos de tronco produjeron inhibición en la germinación o elongación de radícula de lechuga. En cambio, el suelo superficial inhibió la elongación de la radícula hasta en un $60 \%$ con respecto al testigo. Los lixiviados de hojarasca inhibieron la germinación de la lechuga hasta en un $90 \%$. La cantidad de fitotoxinas liberada en condiciones de campo varió según la edad de la hojarasca; la nueva no produjo inhibición en germinación y elongación de la radícula. Sin embargo, al transcurrir el tiempo, la inhibición se presentó y alcanzó un máximo cuando la hojarasca tenía 30 días de edad. En esta fecha la germinación y la elongación de la radícula sólo alcanzaron un $50 \%$ de lo ocurrido con los testigos. Después, la capacidad de inhibición de los lixiviados de hojarasca fue disminuyendo gradualmente hasta que desapareció a los 60 días de edad. Aunque el estudio de Molina et al. (1991) sugiere fuertemente que E. globulus es alelopático, aún queda por demostrar estos efectos en condiciones campo. La toxicidad de la hojarasca de E. globulus en diferentes grados de descomposición y en diferentes suelos también ha sido estudiada por Souto et al. (1994). Se encontraron resultados diferentes a los del equipo de Molina en cuanto a la duración de la toxicidad, pues para Souto y colaboradores la toxicidad fue máxima al principio del proceso de descomposición de las hojas. Posiblemente los resultados de Molina y su equipo son más realistas pues trabajaron con lixiviados naturales, mientras que el otro equipo trabajó con extractos obtenidos después de remojar 24 horas con agua destilada a los restos de las hojas.

En su crítica de la alelopatía, Harper (1977) sugiere que los lixiviados de hojas, si contienen suficiente azúcar, pueden estimular a los microbios del suelo y éstos, después de crecer, hacer que el nitrógeno del suelo sea inaccesible para las plantas. Esto podría producir efectos nocivos en ciertas plantas que podrían atribuirse erróneamente a fitotoxinas. Este argumento supondría que las hojas sanas de plantas presuntamente alelopáticas liberarían cantidades gran- des de azúcar sin perder su integridad física. Esta liberación de azúcar resultaría muy costosa y posiblemente tendría un efecto nocivo sobre la tasa de crecimiento de la planta. Más aun, la existencia de zonas de inhibición debería ser muy común alrededor de plantas que son atacadas por áfidos, pues el ataque de estos animales literalmente produce lluvia de azúcar que los áfidos no utilizan. Los experimentos de May y Ash (1990) y los de Molina et al. (1991) sugieren fuertemente que la explicación de Harper del azúcar lixiviado no es correcta para el caso del eucalipto. Por ejemplo, el suelo donde había crecido eucalipto que fue usado por May y Ash (1990), que supuestamente debería tener inmovilizado el nitrógeno después de mucho tiempo de llover azúcar, no fue inhibidor. En cambio, cuando se adicionó el lixiviado simulando la lluvia, la inhibición se presentó, más aun, los efectos sobre la germinación de lixiviados o extractos de suelo que son aplicados en caja de petri no tienen que ver con inmovilización de nitrógeno.

\section{Discusión general}

La evidencia presentada en esta revisión es convincente en cuanto que varias especies de eucalipto tienen efectos adversos en otras plantas. En varios de estos estudios, los efectos adversos no pueden atribuirse irrefutablemente a la alelopatía, sin embargo tampoco puede excluirse su posible papel nocivo. Otros estudios sugieren fuertemente que los aleloquímicos de los eucaliptos son responsables por una gran variedad de efectos adversos en las plantas. Aunque ningún trabajo reúne irrefutablemente todos los tipos de evidencia necesaria para demostrar alelopatía de eucaliptos, el conjunto de evidencia hace razonable decir que los efectos alelopáticos de varios eucaliptos en condiciones naturales existen. Sin embargo, el tipo de especies afectadas y el grado de afectación es muy variable. También es evidente que la capacidad alelopática varía de acuerdo a la especie del eucalipto. En algunas especies los efectos alelopáticos potenciales no se han detectado o son débiles, mientras que en otras especies son fuertes (Lisanewok y Michelsen, 1993; Cuadro 1). De hecho, en algunas especies de eucalipto algunos tejidos son inhibidores mientras que los mismos tejidos de otras especies no lo son (May y Ash, 1990).

Las distintas partes del eucalipto tienen diferente capacidad para liberar sustancias alelopáticas. En general, cualquier parte molida o pulverizada liberará más metabolitos secundarios que en forma entera. Los estudios realizados con este tipo de material son criticables por su artificialidad (May y Ash, 1990). Si las 
partes son picadas o fragmentadas, su efecto también será mayor que las partes enteras de eucalipto. Los estudios que usan materiales picados podrían ser también criticables por su falta de realismo. Sin embargo, existen esquemas de manejo de plantaciones de eucạlipto en Brasil donde se cosechan grandes extensiones donde los troncos se retiran y las ramas y hojas son picadas, dejadas en la superficie o incorporadas al suelo (F. Gili, comunicación personal). De acuerdo a los estudios de Molina et al. (1991) y de May y Ash (1990), este tipo de manejo causaría una liberación masiva de metabolitos secundarios. El suelo tiene capacidad de retener metabolitos secundarios, pero este tipo de liberación lo saturaría y posiblemente los metabolitos podrían viajar a los mantos freáticos. Aunque no hay mucha investigación sobre los efectos de los metabolitos de eucalipto en organismos acuáticos, se ha reportados que son tóxicos para ciertos peces. Esto sería alelopatía según la definición amplia de Rice (1984). Gehrke et al. (1993) simularon la caída natural de hojarasca (hojas y corteza) de Eucalyptus camaldulensis en estanques con el pez $\mathrm{Ma}$ cquaria ambigua (Richardson); ambas especies pueden tener contacto en Australia, la primera como árbol ripario o de bosques inundados estacionalmente y la segunda como pez nativo dulceacuícola. La hojarasca de eucalipto produjo hipoxia en el agua pero además liberó sustancias tóxicas que en conjunto causaron la muerte de todas las larvas del pez. La aereación del agua aumentó la sobrevivencia de las larvas al $76.6 \%$ con respecto a un testigo aereado sin hojarasca. Las sustancias solubilizadas del eucalipto aplicadas solas produjeron daños en las agallas de los peces juveniles y en concentraciones de $20 \mathrm{~g}$ de corteza por litro causaron su muerte. Sería recomendable investigar el potencial de los metabolitos secundarios del eucalipto para alcanzar los mantos freáticos y ríos y estimar cuáles serían los efectos sobre organismos acuáticos. En caso de que hubiera efectos, habría que diseñar esquemas de manejo en plantaciones donde los residuos se usen para producir composta o se eliminen.

La evidencia presentada también muestra que la actividad alelopática de las partes del eucalipto tiene intensidad diferente de acuerdo con la edad de los tejidos desprendidos del árbol. La actividad de la hojarasca o corteza de algunos eucaliptos dura entre 60 y 90 días, sin que las partes recién desprendidas sean necesariamente más inhibidoras (May y Ash, 1990; Molina et al., 1991). El eucalipto se caracteriza por producir hojarasca continuamente, además de que su tasa de descomposición por organismos del suelo es más lenta que la de hojarasca de otras especies (Toky y Singh, 1993). Por lo anterior, se puede esperar que una plantación de eucalipto va a producir aleloquímicos continuamente. Muchos de estos aleloquímicos son muy solubles en agua y pueden concentrarse en el suelo o en la superficie de las hojas y troncos cuando llueve poco o no llueve. Así, se puede esperar que las lluvias fuertes iniciales de la temporada y las subsecuentes lavarán estos aleloquímicos (May y Ash, 1989; Molina et al., 1991) y dejarán sólo a los aleloquímicos que se retienen en el suelo en sus capas superficiales. Este suelo aun puede interferir con la germinación y crecimiento de varias especies cultivadas; por ejemplo, suelo de plantaciones de $E$. $c i$ tridora (Igboanugo, 1988), E. globulus (Molina et al., 1991), E. tereticornis (Kohli et al., 1990; Singh y Kohli, 1092) y para E. grandis, E. urophylla S.T. Blake y un eucalipto híbrido (Espinosa-García y MartínezHernández, datos no publicados). Evidentemente, la cantidad de aleloquímicos retenida variará con el tipo de suelo. El suelo donde había crecido eucalipto que usaron (May y Ash, 1990) no produjo inhibición en sus plantas experimentales. Esto fue atribuido a la actividad de la edafobiota especializada en degradación de aleloquímicos de eucalipto. Aunque se podría esperar que hubiera evolución de edafobiotas capaces de degradar los aleloquímicos en plantaciones de eucaliptos introducidos, no hay evidencia concluyente para ello. La plantación donde trabajaron Molina et al. (1991) tenía 23 años de edad. Aun así, su suelo resultó inhibidor independientemente de la lluvia que cayó en el período de su estudio. Por el contrario, Del Moral y Müller (1970) encontraron que el suelo bajo hojarasca de eucalipto y el suelo de un pastizal vecino retenían diferencialmente la capacidad de inhibir a Bromus rigidus cuando eran irrigados una vez con lixiviados de hojarasca. La actividad inhibidora desaparecía más rápidamente en suelos usualmente cubiertos por hojarasca, aunque la actividad duraba lo mismo en ambos suelos si se impedía la acción de los microorganismos aerobios.

Muy posiblemente los aleloquímicos que se lavan fácilmente del suelo son ácidos fenólicos del eucalipto. Los aleloquímicos que se retienen posiblemente son compuestos fenólicos ligados al suelo y terpenoides absorbidos al suelo (Whitehead et al. 1983; Nishimura et al., 1984; Barton et al., 1989; Singh et al., 1991). Algunas mediciones en pino (planta rica en terpenoides como el eucalipto) muestran que la hojarasca del pino piñonero produce una atmósfera de terpenoides que puede ser tóxica para varias especies (Wilt et al., 1993). Los compuestos fenólicos frecuentemente han sido reponsabilizados de los efectos alelopáticos del eucalipto (por ejemplo Del Moral y Müller, 1969, 1970; Singh y Kohli, 1992; Souto tt al., 1994, 1995). 
En plantas diferentes al eucalipto se ha mostrado que la concentración de compuestos fenólicos en los tejidos vegetales depende del balance interno carbono/nutrientes de la planta. Si la planta tiene suficientes nutrientes, los productos fotosintéticos serán usados en el crecimiento; si los nutrientes faltan, serán usados en la síntesis de metabolitos secundarios (Herms y Mattson, 1992). Aunque ésto no se ha demostrado para eucaliptos, se puede esperar que así ocurra con estos árboles. Esto implicaría que plantaciones de eucalipto con suelo deficiente en nutrientes producirían y liberarían más compuestos fenólicos que plantaciones sin este problema.

La acumulación de aleloquímicos en los suelos de plantaciones y la habilidad competitiva del eucalipto tienen repercusiones en la composición florística del sotobosque. Únicamente las especies poco sensibles a este suelo y capaces de competir con el eucalipto podrán persistir. Lima (1987) muestra que un sotobosque diverso puede prosperar en una plantación de eucalipto en zonas húmedas. En zonas áridas o semiáridas un sotobosque diverso puede no existir, haciendo que pueda haber problemas de erosión (Alexander, 1989). Cuando una plantación de eucalipto se cosecha y no se renueva para dar otro uso a la tierra, los efectos de los eucaliptos pueden durar algunos meses. Después de este tiempo, el suelo puede volverse adecuado para cultivos si no ha habido erosión (Sanginga y Zwift, 1992). Se ha propuesto que la quema de residuos u hojarasca del eucalipto puede aliviar efectos alelopáticos eliminando fuentes de aleloquímicos y aleloquímicos de la capa superficial del suelo (Bhaskar et al., 1992).

Varias especies de eucalipto pueden tener también efectos nocivos indirectos sobre otras plantas. Es posible que algunas especies de eucalipto inhiban a los hongos y bacterias implicados en la formación de micorrizas o en la formación de nódulos fijadores de nitrógeno (Paulino et al., 1987; Rajashekhara et al., 1989). Aunque el néctar de las flores de algunas especies de eucaliptos es usado extensivamente por abejas europeas (Apis mellifera L.) para producir miel que se explota comercialmente (véase p. ej. MartínezGómez et al., 1993), este néctar puede ser tóxico para especies de polinizadores indígenas. Los árboles en floración de Eucalyptus camaldulensis, situados en los bordes de la reserva ecológica del Pedregal de la Universidad Nacional Autónoma de México, en ciertas épocas del año se ven rodeados por numerosos abejorros (Bombus sp.) muertos (F.J. Espinosa, observación personal). Este fenómeno también se observa en otras áreas de la capital de México (R. Dirzo, comunicación personal). Es posible que su muerte se deba a metabolitos secundarios en el néctar. Si esto se confirmara, E. camaldulensis podría estar afectando indirectamente a otras especies de plantas, pues estaría bajando la probabilidad de que fueran polinizadas y produjeran frutos y semillas.

Muchos de los estudios sobre alelopatía se han concentrado en los efectos de unas cuantas especies introducidas. Los estudios reseñados en el cuadro 1 no fueron seleccionados por la especie de eucalipto que fue estudiada y muy posiblemente representa bien la literatura sobre alelopatía y eucaliptos. En este cuadro, E. globulus, fue estudiado 12 veces al igual que E. tereticornis, E. citridora 5 veces, E. camaldulensis 4 veces y E. grandis y E. macrorhyncha 2 veces cada uno. Aunque se podría alegar que estas pocas especies son las que han dado reputación de alelopáticas, también se han mostrado efectos y/o potencial alelopáticos para otras 9 especies de eucalipto, inclusive en Australia (Del Moral et al., 1978; Ashton y Willis, 1982; Bowman y Kirkpatrik, 1986; May y Ash; 1990). De cualquier manera, el sesgo en el estudio de especies de eucalipto sugiere precaución en cuanto a la suposición de efectos alelopáticos en los cientos de especies de eucalipto nativas y de las más de dos decenas introducidas.

La evaluación completa de los alcances de los efectos alelopáticos del eucalipto requiere de investigación sobre: a) La interacción de los diferentes tipos de suelo con los aleloquímicos del eucalipto. En particular: i) la cantidad de aleloquímicos retenidos y ii) la migración de los aleloquímicos a través del suelo y su posible llegada al manto freático y ríos; $b$ ) la cantidad de aleloquímicos producidos a lo largo del año bajo diferentes esquemas de manejo y después de la cosecha de troncos; $c$ ) la estabilidad de los aleloquímicos en el ambiente y la actividad biológica de los productos derivados naturalmente de los aleloquímicos y d) si los aleloquímicos alcanzan mantos freáticos y ríos, estudiar sus efectos en diferentes concentraciones sobre organismos acuáticos de la región.

Es claro que muchas especies de eucalipto son valiosas pues pueden producir satisfactores para el ser humano de una manera muy eficiente. Sin embargo, también es claro que el uso de estas especies también puede producir problemas ambientales y de otra índole. Las afirmaciones populares acerca de la alelopatía en eucaliptos ("Las plantaciones de eucalipto producen desiertos verdes", "Los eucaliptos envenenan al suelo para otras plantas") pueden ser verdades a medias que no se pueden aplicar a todas las especies de eucalipto en todas las condiciones ambientales en las que se pueden cultivar. Tampoco se puede decir que los efectos alelopáticos y su magnitud son generales sobre todas las especies vegetales. Ciertamente, plantaciones de especies de otros géneros 
también pueden causar problemas ambientales (Poore y Fries, 1985). El conjunto de evidencias presentadas en esta revisión sugiere que las plantaciones de varias especies de eucalipto pueden causar problemas ambientales por alelopatía que dependen de varios factores. Éstos están relacionados con la especie de eucalipto en cuestión, el suelo donde crece, los cultivos o vegetación vecina, el régimen de lluvias, los mantos freáticos y ríos de la región y el manejo de la plantación. Es muy posible que un estudio cuidadoso de todos estos factores determine si una plan- tación de eucalipto puede establecerse en una región sin causar problemas o, en caso contrario, determine cuál es el esquema de manejo que minimice los efectos de la plantación sobre otras especies de plantas.

\section{Agradecimientos}

Agradezco al Dr. Rodolfo Dirzo y a un revisor anónimo la lectura crítica del manuscrito y a Hugo A. Espinosa por su ayuda en la obtención de material bibliográfico

Cuadro 1. Experimentos u observaciones relacionados a la demostración de efectos alelopáticos causados por especies de eucaliptos. Los trabajos de laboratorio están al principio seguidos por los de invernadero y finalmente los de campo. Los reportes que implican dos o más tipos de experimentos se encuentran entre los reportes que sólo usaron un tipo de experimento u observación. Los trabajos consultados como resumen están marcados con (R).

\begin{tabular}{ccccc}
\hline $\begin{array}{c}\text { Especie } \\
\text { Referencia }\end{array}$ & $\begin{array}{c}\text { Tipo de } \\
\text { experimento }\end{array}$ & $\begin{array}{c}\text { Especie } \\
\text { blanco }\end{array}$ & $\begin{array}{c}\text { Variable de } \\
\text { respuesta }\end{array}$ & Efecto
\end{tabular}

\begin{tabular}{|c|c|c|c|c|c|}
\hline $\begin{array}{l}\text { E. globulus } \\
\text { E. citridora } \\
\text { Singh et al., } \\
1991\end{array}$ & $\begin{array}{l}\text { Bioensayos con acei- } \\
\text { tes esenciales de ho- } \\
\text { jas de eucalipto y con } \\
\text { algunos de sus com- } \\
\text { ponentes adsorbidos } \\
\text { al suelo y/o en esta- } \\
\text { do gaseoso. }\end{array}$ & $\begin{array}{c}\text { Phaseolus } \\
\text { aureus }\end{array}$ & $\begin{array}{l}\text { Germinación, cre- } \\
\text { cimiento y conte- } \\
\text { nido de agua de } \\
\text { plántulas. }\end{array}$ & $\begin{array}{l}\text { Inhibición del crecimiento y con- } \\
\text { tenido de agua bajo en las plántu- } \\
\text { las con concentraciones bajas y } \\
\text { altas de aceites esenciales y sus } \\
\text { componentes adsorbidos y/o va- } \\
\text { porizados sobre el suelo. La ger- } \\
\text { minación sólo se inhibió con } \\
\text { concentraciones medias o altas de } \\
\text { los aceites esenciales. }\end{array}$ & $\begin{array}{l}\text { No hay elementos } \\
\text { para juzgar si las } \\
\text { concentraciones } \\
\text { usadas en los bioen- } \\
\text { sayos simulan las } \\
\text { concentraciones de } \\
\text { aleloquímicos en } \\
\text { suelo o atmósferas } \\
\text { naturales. }\end{array}$ \\
\hline $\begin{array}{l}\text { E. globulus } \\
\text { Konar \& } \\
\text { Kushari. } \\
1989\end{array}$ & $\begin{array}{l}\text { Bioensayo de labo- } \\
\text { ratorio con lixivia- } \\
\text { dos foliares de un } \\
\text { eucalipto y Mangifera } \\
\text { indica, Shorea ro- } \\
\text { busta y Tectona } \\
\text { grandis. }\end{array}$ & Costus speciosus & $\begin{array}{l}\text { Número de brotes } \\
\text { y crecimiento en } \\
\text { rizomas; concen- } \\
\text { tración de dios- } \\
\text { genina en los } \\
\text { rizomas. }\end{array}$ & $\begin{array}{l}\text { Los lixiviados de eucalipto inhi- } \\
\text { bieron el crecimiento y el número } \\
\text { de brotes en los rizomas. Además, } \\
\text { los rizomas tuvieron menos diosge- } \\
\text { nina que los rizomas no tratados o } \\
\text { tratados con lixiviados de las otras } \\
\text { especies. Los rizomas tratados con } \\
\text { lixiviados de las otras especies in- } \\
\text { crementaron su porcentaje de bro- } \\
\text { tes, acortaron el tiempo necesario } \\
\text { para brote y promovieron el creci- } \\
\text { miento subsecuente. Además, su } \\
\text { contenido de diosgenina no fue } \\
\text { afectado o se incrementó. }\end{array}$ & $\begin{array}{l}\text { Los lixiviados fueron } \\
\text { obtenidos por remo- } \\
\text { jo de hojas enteras. }\end{array}$ \\
\hline $\begin{array}{l}\text { Eucalyptus } \\
\text { camaldulensis } \\
\text { E. tereticornis } \\
\text { Sanker \& } \\
\text { Rai, } 1993 \\
\text { (R) }\end{array}$ & $\begin{array}{l}\text { No se especifica, po- } \\
\text { siblemente en labo- } \\
\text { ratorio. } \\
\text { Lixiviados por remo- } \\
\text { jo de semillas } 24 \text { o } \\
48 \text { hrs. }\end{array}$ & $\begin{array}{l}\text { Capsicum sp. } \\
\text { Lycopersicum sp. } \\
\text { Solanum } \\
\text { melanogena } \\
\text { Abelmoschus } \\
\text { esculentus } \\
\text { Vigna } \\
\text { unguiculata }\end{array}$ & Germinación. & $\begin{array}{l}\text { Inhibición en chile y jitomate. El } \\
\text { resto de las especies no fueron in- } \\
\text { hibidas. }\end{array}$ & $\begin{array}{l}\text { No se menciona can- } \\
\text { tidad de semilla usa- } \\
\text { da para remojar ni en } \\
\text { qué volumen de } \\
\text { agua. Información in- } \\
\text { suficiente para juzgar } \\
\text { realismo del experi- } \\
\text { mento. }\end{array}$ \\
\hline
\end{tabular}




$\begin{array}{cccccc}\text { Especie } & \text { Tipo de } & \text { Especie } & \text { Variable de } \\ \text { respuesta } & \text { Efanco } & \text { Comentarios }\end{array}$

\begin{tabular}{|c|c|c|c|c|c|}
\hline $\begin{array}{l}\text { Eucalyptus } \\
\text { youmanii } \\
\text { Eucalyptus } \\
\text { macrorhyncha } \\
\text { Bansal et al., } \\
1992\end{array}$ & $\begin{array}{l}\text { Extractos acuosos de } \\
\text { hojas (remojo) con y } \\
\text { sin carbón activado } \\
\text { en cajas petri. }\end{array}$ & $\begin{array}{l}\text { Triticum } \\
\text { aestivum (dos } \\
\text { variedades) } \\
\text { Raphanus } \\
\text { sativus }\end{array}$ & $\begin{array}{l}\text { Crecimiento de } \\
\text { plántulas }\end{array}$ & $\begin{array}{l}\text { E. macrorhyncha solo inhibió fuer- } \\
\text { temente a una variedad de trigo. } \\
\text { E. youmanii inhibió raíz y tallo de } \\
\text { una variedad de trigo mientras que } \\
\text { la otra variedad fue estimulada. El } \\
\text { carbón activado disminuyó signifi- } \\
\text { cativamente los efectos. }\end{array}$ & $\begin{array}{l}\text { Muestra inhibición } \\
\text { dependiente de la } \\
\text { concentración. Tam- } \\
\text { bién inhibición dife- } \\
\text { rencial que depende } \\
\text { de la especie y del tipo } \\
\text { de variedad dentro de } \\
\text { una especie. }\end{array}$ \\
\hline $\begin{array}{l}\text { Eucalyptus } \\
\text { sp. (brasileño) } \\
\text { Bruna et al., } \\
1989 \text { (R) }\end{array}$ & $\begin{array}{l}\text { Extractos acuosos de } \\
\text { hojarasca en cajas } \\
\text { petri. }\end{array}$ & $\begin{array}{l}\text { Microbiota del } \\
\text { suelo. }\end{array}$ & $\begin{array}{l}\text { Crecimiento de } \\
\text { colonias micro- } \\
\text { bianas en cajas } \\
\text { petri. }\end{array}$ & $\begin{array}{l}\text { Crecimiento bacteriano fuerte- } \\
\text { mente inhibido, número de colo- } \\
\text { nias de hongos no afectado. }\end{array}$ & $\begin{array}{l}\text { Resumen demasiado } \\
\text { escueto. }\end{array}$ \\
\hline $\begin{array}{l}\text { E. tereticornis } \\
\text { Nandal et } \\
\text { al., } 1992 . \\
\text { (R) }\end{array}$ & $\begin{array}{l}\text { Extractos acuosos de } \\
\text { hojas senescentes. }\end{array}$ & $\begin{array}{l}\text { Raphanus sativus } \\
\text { Allium cepa } \\
\text { Solanum } \\
\text { melongena } \\
\text { Trigonella } \\
\text { foenumgraecum }\end{array}$ & $\begin{array}{l}\text { Germinación y } \\
\text { crecimiento de } \\
\text { plántulas. }\end{array}$ & $\begin{array}{l}\text { Efectos inhibidores que variaron } \\
\text { con la concentración del extrac- } \\
\text { to. En algunos casos hubo efectos } \\
\text { estimulantes. }\end{array}$ & $\begin{array}{l}\text { También se probaron } \\
\text { extractos de hojas de } \\
\text { Populus deltoides, } \\
\text { que también fue in- } \\
\text { hibidor. }\end{array}$ \\
\hline $\begin{array}{l}\text { Eucalipto } \\
\text { híbrido } \\
\text { (E. tereticornis) } \\
\text { Sharma et } \\
\text { al., } 1987 \text { (R) }\end{array}$ & $\begin{array}{l}\text { Lixiviados de hojas } \\
\text { en cajas de petri. }\end{array}$ & $\begin{array}{l}\text { Triticum } \\
\text { aestivum } \\
\text { Brassica juncea } \\
\text { Pisum sativum } \\
\text { Lens esculenta }\end{array}$ & $\begin{array}{l}\text { Germinación y } \\
\text { crecimiento de } \\
\text { plántulas. }\end{array}$ & $\begin{array}{l}\text { La germinación de } B \text {. juncea fue } \\
\text { afectada. Para los demás cultivos } \\
\text { la inhibición fue ligera. El creci- } \\
\text { miento y vigor de todos los culti- } \\
\text { vos fue inhibido. El eucalipto } \\
\text { ocupó el tercer lugar de inhibición } \\
\text { en un grupo de cuatro especies de } \\
\text { árboles. }\end{array}$ & $\begin{array}{l}\text { Se probaron otras } \\
\text { tres especies de ár- } \\
\text { boles como fuente de } \\
\text { alelopáticos (Acacia } \\
\text { nilotica, Dalbergia } \\
\text { sissoo, Morus alba). } \\
\text { Se documentó la } \\
\text { susceptibilidad dife- } \\
\text { rencial de los cultivos } \\
\text { a los lixiviados. }\end{array}$ \\
\hline $\begin{array}{l}\text { E. citridora } \\
\text { Nishimura et } \\
\text { al., } 1984\end{array}$ & $\begin{array}{l}\text { Bioensayos con } p \text { - } \\
\text { mentano-3-8-dioles } \\
\text { de hojas de eucalip- } \\
\text { to en diferentes } \\
\text { concentraciones; de- } \\
\text { tección de los alelo- } \\
\text { químicos en suelo. }\end{array}$ & $\begin{array}{l}\text { Echinochloa } \\
\text { crusgalli } \\
\text { Eucalyptus } \\
\text { citridora } \\
\text { Lactuca sativa } \\
\text { Lepidium } \\
\text { sativum } \\
\text { Oryza sativa } \\
\text { Setaria viridis }\end{array}$ & $\begin{array}{l}\text { Germinación y } \\
\text { crecimiento de } \\
\text { plántulas. }\end{array}$ & $\begin{array}{l}\text { Inhibición diferencial según las es- } \\
\text { pecies. Para germinación, entre } 0 \\
\text { y } 20 \% \text { a } 30 \mathrm{ppm} \text { de concentra- } \\
\text { ción y } 2 \text { y } 100 \% \text { con } 300 \text { ppm. } \\
\text { Para plántulas entre } 0 \text { y } 8 \% \text { con } \\
10 \text { ppm y entre } 2 \text { y } 100 \% \text { con } 300 \\
\text { ppm. Las semillas y plántulas más } \\
\text { resistentes fueron Oryza sativa y } \\
\text { Eucalyptus citridora. }\end{array}$ & $\begin{array}{l}\text { Asilados de las hojas } \\
\text { y del suelo de bos- } \\
\text { que australiano de } \\
\text { eucalipto. La con- } \\
\text { centración de los } \\
\text { aleloquímicos es ese } \\
\text { suelo fue de } 15 \text { ppm. } \\
\text { Los autores especu- } \\
\text { lan que su método } \\
\text { de extracción fue in- } \\
\text { eficiente y/o los } \\
\text { aleloquímicos fue- } \\
\text { ron degradados por } \\
\text { microbios. }\end{array}$ \\
\hline $\begin{array}{l}\text { E. tereticornis } \\
\text { Joshi et al., } \\
1992(\mathrm{R})\end{array}$ & $\begin{array}{l}\text { Bioensayo de labora- } \\
\text { torio donde las se- } \\
\text { millas se embebieron } \\
\text { en extractos acuosos } \\
\text { de hojarasca fresca y } \\
\text { de parcialmente des- } \\
\text { compuesta. Se midió } \\
\text { la concentración de } \\
\text { fenoles en los extrac- } \\
\text { tos. También se tra- } \\
\text { bajó con hojarasca } \\
\text { de otras } 9 \text { especies } \\
\text { de árboles. }\end{array}$ & $\begin{array}{l}\text { Brassica juncea } \\
\text { Pisum sativum } \\
\text { Triticum } \\
\text { aestivum } \\
\text { Zea mays }\end{array}$ & Germinación. & $\begin{array}{l}\text { Inhibición mayor con hojarasca } \\
\text { fresca. El grado de inhibición es- } \\
\text { tuvo relacionado directamente al } \\
\text { contenido de fenoles en los ex- } \\
\text { tractos. El eucalipto estuvo en el } \\
\text { grupo de árboles más inhibidores. } \\
B \text {. juncea y } P \text {. sativum fueron más } \\
\text { inhibidos que el trigo y el maíz. }\end{array}$ & $\begin{array}{l}\text { Las otras especies de } \\
\text { árboles cuya hojaras- } \\
\text { ca fue probada son: } \\
\text { Albizzia lebbeck } \\
\text { Azadirachta indica } \\
\text { Bombax ceiba } \\
\text { Casuarina } \\
\text { equiesetifolia } \\
\text { Dalbergia sisoo } \\
\text { Leucaena } \\
\text { leucocephala } \\
\text { Populus deltoides } \\
\text { Sesbania aculeata } \\
\text { Syzyngium cumini. }\end{array}$ \\
\hline
\end{tabular}




\begin{tabular}{ccccc}
$\begin{array}{c}\text { Especie } \\
\text { Referencia }\end{array}$ & $\begin{array}{c}\text { Tipo de } \\
\text { experimento }\end{array}$ & $\begin{array}{c}\text { Especie } \\
\text { blanco }\end{array}$ & $\begin{array}{c}\text { Variable de } \\
\text { respuesta }\end{array}$ & Efecto \\
\hline
\end{tabular}

E. globulus Dominguez et al., 1988 (R)

E. globulus

Souto et. al., 1994

E. globulus

Souto et al., 1995

E. globulus

Del Moral \& Muller, 1969

Bioensayos en caja de Petri con condensados de niebla por hojas de eucalipto y por lixiviados de hojas obtenidos con agua rociada.

Bromus rigidus Festuca

megalura

Bromus mollis Lolium multiflorum Avena fatua Hordeum leporinum Eucalyptus globulus
Germinación en Germinación normal en suelo. In No se especifica la suelo germinación, vitro para lechuga, inhibición del edad de la hojarasca in vitro $47 \%$ en extractos enteros y $24 \%$ en extractos sin polifenoles. Para eucalipto no hay inhibición ni cómo fueron irrigadas las macetas. También se probaron otras especies de árboles como fuente de alelopáticos. El eucalipto fue el más inhibidor para la lechuga.

Germinación y Las hojas de eucalipto fueron tóxicas elongación de la para germinación sin importar el radícula suelo en que se descompusieron los primeros 30 días. La inhibición de crecimiento se mantuvo hasta 180 días. Después de esos periodos el suelo se vuelve importante preservando la toxicidad de la hojarasca de eucalipto y haciendo que se vuelvan tóxicas las hojarascas de otras tres especies. Los suelos de eucalipto y acacia son los más inhibidores, hasta 180 días para la germinación y hasta 365 días para el crecimiento.

Germinación y La mayoría de los compuestos fenóelongación de la licos inhibieron de un 40 al $100 \%$ la radícula germinación o el crecimiento de las especies en una concentración de 5 mM. La inhibición fue leve o media en concentraciones de $1 \mathrm{mM}$ o menos para L. sativa, aunque algunos aleloquímicos fueron estimulantes en estas concentraciones. El suelo de eucalipto no inhibió la germinación de las especies aunque sí redujo en un $40 \%$ la elongación de la radícula de Dactylis glomerata. El sueio de acacia fue más inhibidor que el de eucalipto. Los extractos de hojarasca en descomposición fueron tóxicos para lechuga hasta 30 días. A los 180 o 365 días ya no fueron tóxicos.

Elongación radicular.

El agua condensada por las hojas de el eucalipto colectada en seis eventos de neblina redujo la elongación de la radícula de $B$. rigidus (la única planta usada en este experimento) en todos los eventos. La inhibición fue mayor en algunos eventos cuando la neblina duró menos y por lo tanto los aleloquímicos estuvieron menos concentrados. Los lixiviados artificiales redujeron el crecimiento radicular de las especies en 78 al $47 \%$ con respecto al testigo (agua destilada).
Se detectaron en hojas y corteza los compuestos fenólicos que se ensayaron puros. Para el caso de los extractos no hay elementos para juzgar si las concentraciones usadas en los bioensayos simulan las concentraciones de aleloquímicos en suelo natural.

Los aleloquímicos fueron detectados en los condensados naturales y artificiales. Los principales ácidos fenólicos fueron: elágico, clorogénico, p-coumarilquínico y gentísico. También se detectaron taninos. 


\begin{tabular}{cccccc}
\hline $\begin{array}{c}\text { Especie } \\
\text { Referencia }\end{array}$ & $\begin{array}{c}\text { Tipo de } \\
\text { experimento }\end{array}$ & $\begin{array}{c}\text { Especie } \\
\text { blanco }\end{array}$ & $\begin{array}{c}\text { Variable de } \\
\text { respuesta }\end{array}$ & Efecto & Comentarios
\end{tabular}

Eucalyptus camaldulensis

E. globulus

E. saligna

Lisanework \& Michelsen, 1993

\section{E. globulus}

Molina et al., 1991

E. globulus ssp. bicostata E. maculata Eucalyptus macrorhyncha E. rossii

E. rubida

May \& Ash, 1990
Bioensayos en cajas petri y experimentos con macetas irrigadas con extractos en varias concentraciones. Las plántulas en maceta se irrigaron durante todo el experimento con una solución de nutrientes.

Bioensayos en cajas petri con lixiviados naturales de hojas en pie, de hojarasca, escurrimiento de tallos y . percolados de suelo. Los lixiviados, percolados y escurrimientos fueron colectados durante 6 meses después de cada evento de lluvia.

Bioensayos en cajas petri o en macetas con lixiviados de hojas, hojarasca y escurrimientos de tallo. Las soluciones resultantes fueron obtenidas simulando eventos naturales o directamente en el campo durante o después de las lluvias. También bioensayos con volátiles de hojas frescas y experimentos para mostrar si los aleloquímicos se acumulaban en el suelo.
Cicer arietinum Eragrostis tef Pisum sativum Zea mays

Lactuca sativa

Lolium perenne Lemna minor Eucalyptus globulus Acacia saligna
Germinación y crecimiento de plántulas.

Germinación y elongación de radícula; crecimiento de plántulas.

Germinación y/o crecimiento de plántulas; crecimiento de plantas de Lemna minor.
Cicer arietinum fue afectado severamente en su germinación con todas las concentraciones de los extractos de todas las especies de árboles. El maíz sólo sufrió inhibición ligera con altas concentraciones de extracto de $E$. camaldulensis y E. saligna. La germinación de los otros dos cultivos se inhibió progresivamente de acuerdo al incremento de la concentración del extracto. E. globulus fue menos inhibidor que las otras dos especies de eucalipto. La elongación de radícula de todas las especies blanco fue inhibida. Todos los extractos de todas las plantas fuente redujeron el peso seco de las plántulas de maceia de todas las especies blanco sin importar la concentración del extracto.

Los lixiviados de hojas en pie y los percolados de suelo solo resultaron inhibidores sólo un día. El contacto directo con suelo superficial no inhibió la germinación pero redujo hasta $60 \%$ la elongación de la radícula en 17 de los 20 eventos de lluvia. Los lixiviados de hojarasca no fueron inhibidores el primer día después de su caída, pero su acción sobre la germinación y largo de radícula se incrementó hasta alcanzar un 50\% de inhibición a los 30 días de edad de la hojarasca. La inhibición bajó gradualmente hasta desaparecer a los 45 días.

Ninguna de las soluciones de los eucaliptos, excepto lixiviados de hojarasca y corteza desprendida de $E$. macrorhyncha y $E$. rossii respectivamente, fueron inhibidoras en cajas petri. Las plántulas blanco en maceta fueron mediana o fuertemente inhibidas por lixiviados de hojarasca y de corteza de E. rubida. La actividad de los lixiviados disminuye con la edad de la hojarasca en el campo y algunos compuestos inhibidores permanecen activos en material de 5 meses de edad. Los suelos que fueron regados con lixiviados durante 10 días se volvieron inhibidores de la germinación de Lolium perenne. Se logró el mismo efecto con suelo regado una vez con lixiviados concentrados $10 \mathrm{X}$
No se dan elementos para juzgar si las concentraciones usadas simulaban concentraciones naturales. También se probaron extractos de Cupressus lusitanica. Se documentó susceptibilidad diferencial de los cultivos y potencial alelopático diferencial para los cuatro especies de árbol. Trabajo hecho en Etiopía.

Las concentraciones de los lixiviados de hojarasca estuvieron dentro del rengo natural hallado en la plantación.

Trabajo realizado en Australia. 


\begin{tabular}{ccccc}
\hline $\begin{array}{c}\text { Especie } \\
\text { Referencia }\end{array}$ & $\begin{array}{c}\text { Tipo de } \\
\text { experimento }\end{array}$ & $\begin{array}{c}\text { Especie } \\
\text { blanco }\end{array}$ & $\begin{array}{c}\text { Variable de } \\
\text { respuesta }\end{array}$ & Efecto \\
\hline
\end{tabular}

Eucalyptus
camaldulensis
E. grandis,
E. tereticornis
y eucalipto
híbrido
Shivanna et
al., 1992 (R)

Eucalyptus sp.

Paulino et al., 1987

E. globulus

E. citridora

Kohli \&

Singh, 1991

E. tereticornis

Bhaskar et al. 1992

(R)
Experimento de invernadero con suelos con y $\sin$ antecedentes de cultivo de eucalipto y con y sin raíces y hojas de eucalipto.

Bioensayos con aceites esenciales de hojas de eucalipto y con algunos de sus componentes en estado gaseoso. Pruebas en cajas de petri y con plantas en macetas pequeñas.

Experimento en invernadero con hojarasca molida quemada (cenizas) y sin quemar en proporciones de 5 al $50 \%$ del peso del suelo (arena) de la maceta.

Bioensayos en mace-

\section{E. globulus}

Konar \&

Kushari,

1995 tas con lixiviados de hojas juveniles, maduras y senescentes en tres concentraciones

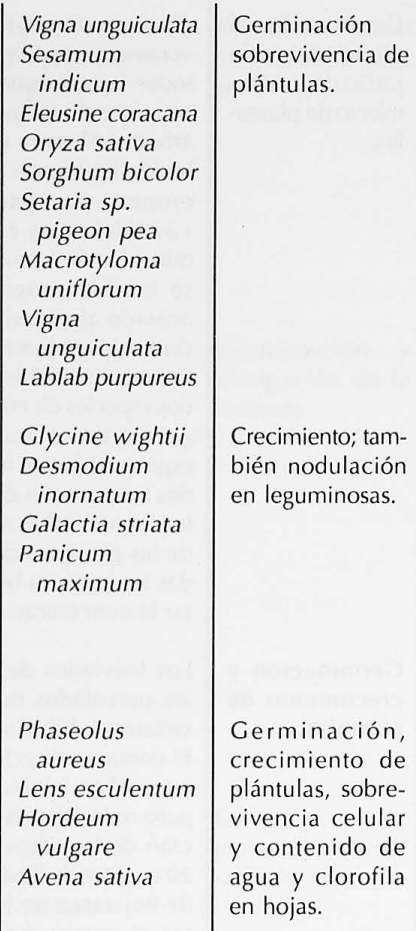

Eleusine

coracana

Costus speciosus

Concentración de clorofila, nitrógeno foliar $y$ diosgenina en rizomas; biomasa.
El pasto no fue inhibido bajo ninguna condición experimental. Las leguminosas fueron inhibidas en su crecimiento y nodulación en los suelos con historial de eucalipto. Las hojas secas de eucalipto incorporadas al suelo inhibieron el crecimiento y nodulación de las leguminosas.

Reducción en todas las variables, $P$. aureus fue el menos afectado, el aceite de E. citridora tuvo un efecto inhibidor más fuerte que el aceite de E. globulus. El limoneno y cineol puros tuvieron efectos diferenciales sobre las especies blanco.

Autores atribuyen efecto a estrés hídrico y competencia. No se especifica diseño experimental. Los autores atribuyen las reducciones a alelopatía, aunque indica que fueron pequeñas $(10 \%$ de reducción).

Se corrigió la acidez de los suelos, para que ambos tuvieran el $\mathrm{pH}$ óptimo para cada tipo de cultivo. También se fertilizaron ambos suelos.

No hay elementos para juzgar si las concentraciones usadas en los bioensayos simulan las condiciones naturales. Los autores proponen que el efecto alelopático ocurre debido a la interferencia de los aleloquímicos con procesos de respiración y fotosintéticos.

La germinación fue inhibida a partir de una proporción del 15\% de hojarasca molida y sin quemar. La altura y número de hojas en las plántulas también se redujeron. Las cenizas de hojarasca no tuvieron efecto inhibidor $y$ hasta estimularon la germinación comparada con las macetas testigo (arena sola).

Todos los lixiviados fueron inhibidores para todas las variables $\sin$ importar la edad de la hoja lixiviada. A mayor concentración del lixiviado, mayor inhibición.
Los autores concluyen que la quema elimina las propiedades alelopáticas de la hojarasca de $E$. tereticornis. Sin embargo, no se controló el efecto de la materia orgánica añadida sobre la disposición de nutrientes, por lo que la ausencia de efectos alelopáticos solo puede aplicarse a la ausencia de inhibición en la germinación.

Los lixiviados fueron obtenidos por remojo de hojas enteras. 


\begin{tabular}{|c|c|c|c|c|c|}
\hline $\begin{array}{c}\text { Especie } \\
\text { Referencia }\end{array}$ & $\begin{array}{c}\text { Tipo de } \\
\text { experimento }\end{array}$ & $\begin{array}{l}\text { Especie } \\
\text { blanco }\end{array}$ & $\begin{array}{l}\text { Variable de } \\
\text { respuesta }\end{array}$ & Efecto & Comentarios \\
\hline
\end{tabular}

\section{E. tereticornis \\ Sidhu \& \\ Hans, 1988 \\ (R) \\ Eucalyptus camaldulensis \\ Experimento de in- vernadero con mace- tas con suelo adicio- nado con $0,1,3 \mathrm{y}$ $5 \%$ de ramas con hojas picadas. La mitad de las macetas fueron fertilizadas con NPK. \\ Cajas con fragmen- tos de hojas, raíces y hojarasca.}

Onyewotu \& Stigter, 1995

E. tereticornis

Dalal et al., 1992 (R)

\section{E. citridora}

Igboanugo,

1988a.

\section{E. tereticornis}

Basu et al., 1987 (R)
Observaciones de campo cerca de árboles en zonas áridas.

Experimento de campo sembrando plántulas de 3.5 semanas a diferentes distancias del lado sur de eucaliptos y de acacias (testigo). Las plántulas fueron. regadas

Observaciones de campo en cultivos sembrados cerca de hileras de eucaliptos. (papa y trigo) y de hileras de árboles Glyricidia sp. (papa).

\begin{tabular}{l|l|l}
$\begin{array}{l}\text { Triticum } \\
\text { aestivum }\end{array}$ & $\begin{array}{l}\text { Peso seco, nú- } \\
\text { mero de brotes } \\
\text { por planta y altu- } \\
\text { ra, en plantas de } \\
\text { ca. 150 días. }\end{array}$ & $\begin{array}{l}\text { Todas las plantas en suelo adicio- } \\
\text { nado crecieron significativamente } \\
\text { menos que-las plantas testigo. La } \\
\text { reducción fue mayor mientras más } \\
\text { biomasa de eucalipto fue adicio- } \\
\text { nada. La presencia de fertilizante } \\
\text { no mejoró significativamente el } \\
\text { desempeño de las plantas que cre- } \\
\text { cieron en el suelo con eucalipto. }\end{array}$ \\
$\begin{array}{ll}\text { Pennisetum } \\
\text { tiphoides }\end{array}$ & No se indica. & $\begin{array}{l}\text { Los autores mencionan que el } \\
\text { experimento de alelopatía "dió re- } \\
\text { sultados inconsistentes", pero no } \\
\text { se presentan tablas de estos resul- } \\
\text { tados. Tampoco se explica el di- } \\
\text { seño ni detalles del experimento. }\end{array}$
\end{tabular}

Varios cultivos (no especificados en el resumen).

\section{Capsicum} annuum

Solanum tuberosum Triticum aestivum $y$ estimadores de crecimiento vegetal.

Crecimiento y rendimiento.

Rendimiento $y$ tamaño de papa. Tamaño en trigo.
Zonas desnudas
Inhibición, aunque menos que otras tres especies de otros géneros de árboles.

Las plántulas de chile a $2 \mathrm{~m}$ de eucalipto murieron. El rendimiento se fue incrementando hasta que fue máximo a los $8 \mathrm{~m}$ de distancia del eucalipto. La acacia no tuvo efecto negativo sobre el chile.

El rendimiento de la papa y el trigo del tubérculo en los surcos cercanos al eucalipto. La papa cerca de Glyricidia sp. no sufrió reducción, El rendimiento no se afectó a 19.8 $\mathrm{m}$ del eucalipto para la papa. se redujo al igual que el tamaño
La adición de ramas y hojas picadas al suelo no simula la caída natural de hojarasca.

Además el picado aumenta artificialmente la cantidad de aleloquímicos que se liberan en el suelo.

Puesto que no hay datos no se puede saber si la conclusión de los autores de que no hay efectos alelopáticos es correcta. La mayor parte del artículo es una reseña de otro donde se muestra que la competencia por agua es importante en la reducción del rendimiento del Pennisetum tiphoides (Onyewotu et al., 1994).

No se sabe si los efectos se deben a alelopatía o a otro factor. Se probaron 7 especies de árboles de diferentes géneros.

La competencia por agua queda excluida al igual que el efecto de sombra. No se controló el contenido de nutrientes del suelo. Cerca de los eucaliptos había materia orgánica baja y $\mathrm{pH}$ bajo. Sin embargo M.O. alta cerca de acacias no mejoró el rendimiento de chiles.

La competencia por agua se excluyó porque había un canal entre los árboles y los cultivos. Los suelos de los diferentes surcos no difirieron en $\mathrm{C}$ y $\mathrm{N}$ orgánicos, CEC, $P$ disponible ni $\mathrm{Ca}$, $\mathrm{Mg}$, Na y K intercambiables. Solo difirie- 


\begin{tabular}{|c|c|c|c|c|c|}
\hline $\begin{array}{c}\text { Especie } \\
\text { Referencia }\end{array}$ & $\begin{array}{c}\text { Tipo de } \\
\text { experimento }\end{array}$ & $\begin{array}{l}\text { Especie } \\
\text { blanco }\end{array}$ & $\begin{array}{l}\text { Variable de } \\
\text { respuesta }\end{array}$ & Efecto & Comentarios \\
\hline
\end{tabular}

\section{Eucalyptus
citridora \\ Eucalyptus camaldulensis \\ E. grandis \\ Igboanugo, $1988 b$ \\ Eucalyptus camaldulensis}

Del Moral \& Muller, 1970

\section{E. baxteri}

Del Moral et al., 1978
Experimento entre plantación rala con 3 especies de eucalipto y pastizal de sabana.

Observaciones de campo (luz, agua nutrientes, cobertura vegetal, incidencia de plántulas). Análisis de aleloquímicos de material vegetal y de suelo. Bioensayos en laboratorio con aleloquímicos y partes vegetales. Experimentos de campo con hojarasca, tipo de suelo y humedad del suelo.

Observaciones $y$ mediciones de campo, bioensayos en caja de petri.

\begin{tabular}{|c|c|}
\hline $\begin{array}{l}\text { Vigna } \\
\text { unguiculata } \\
\text { Zea mays } \\
\text { Sorghum } \\
\text { bicolor }\end{array}$ & $\begin{array}{l}\text { Rendimiento y } \\
\text { crecimiento de } \\
\text { los cultivos. }\end{array}$ \\
\hline $\begin{array}{l}\text { Pastizales intro- } \\
\text { ducidos en Cali- } \\
\text { fornia. } \\
\text { Avena fatua } \\
\text { Bromus rigidus } \\
\text { Bromus mollis } \\
\text { Eucalyptus } \\
\text { camaldulensis } \\
\text { Festuca } \\
\text { megalura } \\
\text { Hordeum } \\
\text { leporinum } \\
\text { Trifolium hirtum }\end{array}$ & $\begin{array}{l}\text { Crecimiento, } \\
\text { sobrevivencia, } \\
\text { abundancia, } \\
\text { germinación, } \\
\text { retención de } \\
\text { aleloquímicos } \\
\text { por diferentes } \\
\text { tipos de suelo }\end{array}$ \\
\hline $\begin{array}{l}\text { Especies de cha- } \\
\text { parral costero } \\
\text { Casuarina } \\
\text { pusilla } \\
\text { Eucalyptus } \\
\text { viminalis } \\
\text { Triticum } \\
\text { aestivum }\end{array}$ & $\begin{array}{l}\text { Distribución es- } \\
\text { pacial de espe- } \\
\text { cies; germinación. }\end{array}$ \\
\hline
\end{tabular}

ron en $\mathrm{pH}$, pues los suelos cerca de eucalipto fueron más ácidos que los de Glyricidia sp. o los lejanos al eucalipto.

Vigna fue inhibida en su rendimiento en la plantación $135 \mathrm{~kg} / \mathrm{ha}$ vs. $658.9 \mathrm{~kg} / \mathrm{ha}$ en pastizal. La fertilización con NPK disminuye parcialmente la inhibición (473.7 vs $886.2 \mathrm{~kg} / \mathrm{ha}$ ). No hay efecto de los eucaliptos en maíz y sorgo.

Se documentó inhibición severa en la vegetación anual en el área de influencia de los eucaliptos. El patrón no se explica por la acción de los herbívoros o granívoros ni por competencia por luz o nutrientes. La competencia por agua es importante pero no explica la ausencia de plantas en esa zona. Se aislaron terpenos de eucalipto que estaban adsorbidos en el suelo; los terpenos adsorbidos fueron tóxicos para la germinación de varias especies.

Se identificaron 10 compuestos fenólicos de hojarasca que fueron inhibidores en bioensayo para la germinación de Bromus rigidus. El tipo de suelo arenoso no permite la acumulación de aleloquímicos por lo que no se observan efectos inhibidores. La microbiota del suelo bajo la influencia del eucalipto descompone más rápido los aleloquímicos que la microbiota de suelos $\sin$ la influencia del árbol.

Se confirmó cuantitativamente que varias especies de chaparral no crecen bajo la copa de E. baxteri. No hubo diferencias significativas en luz o humedad bajo la copa de E. baxteri comparado con otras especies de chaparral. El contenido de nutrientes tampoco mostró diferencias. Los extractos o lixiviados de hojas u hojarasca inhibieron la germinación de las especies blanco.
No se diseñó el experimento para separar alelopatía de la comNo hubo diferencias significativas en iluminación entre la plantación y sabana.

La falta de acción de herbivoros o granivoros no se documentó experimentalmente a diferencia de otros factores donde hubo experimentos de campo y/o laboratorio.

Sólo se midió nitrógeno total en el suelo. Trabajo realizado en Australia. petencia por agua. 


\begin{tabular}{|c|c|c|c|c|c|}
\hline $\begin{array}{c}\text { Especie } \\
\text { Referencia }\end{array}$ & $\begin{array}{c}\text { Tipo de } \\
\text { experimento }\end{array}$ & $\begin{array}{l}\text { Especie } \\
\text { blanco }\end{array}$ & $\begin{array}{c}\text { Variable de } \\
\text { respuesta }\end{array}$ & Efecto & Comentarios \\
\hline
\end{tabular}

Eucalipto
híbrido
(Posiblemente
un híbrido
de E.
tereticornis)
Tomar et al.,
1992

Eucalyptus Camaldulensis

Sanginga \& Swift, 1992

Eucalyptus delegatensis

Bowman \& Kirkpatrick, 1986.

\section{E. regnans}

Ashton \& Willis, 1982
Experimentos de Triticum campo para evaluar aestivum los efectos de coberturas de hojarasca (ton/ha) en trigo $y$. maíz. También se probaron coberturas de hojarasca de otras cuatro especies de árboles.

Bioensayos con extractos de hojas verdes y hojarasca molidas .

Experimentos de invernadero con macetas con suelo de plantación de eucalipto adicionado con hojas verdes y hojarasca de $E$. grandis aplicadas únicamente el primer año. Mediciones de campo de nutrientes en sitios con y sin plantación de eucalipto.

Experimentos de. Eucalyptus campo, con macetas delegatensis y de laboratorio para probar la importancia relativa de la competencia y alelopatía. Para esta última se usaron extractos de hojas, lixiviados y sobreposición de hojarasca.

Experimentos de laboratorio, macetas en invernadero y de campo para tratar de explicar la falta de regeneración natural del Bosque de E. regnans. Para determinar si había alelopatía se usaron extractos $y$ lixiviados foliares, lipidos cuticulares de las hojas acumulados en el suelo, raíces viejas y vivas de $E$.
Nivel de humedad del suelo, nivel de nutrientes y $\mathrm{pH}$ en el suelo, rendimiento de grano.

\section{Zea mays}

Germinación, peso seco de los tallos de las plantas en macetas.

Germinación y crecimiento de plántulas y brinzales.

\section{Eucalyptus} regnans

Germināción y crecimiento de
El rendimiento en grano y paja de trigo y maíz mejoró o no fue diferente del testigo con la hojarasca de cualquiera de las cinco especies de árboles probadas. Las hojarascas aumentaron con el tiempo la retención de humedad y los nutrientes en el suelo; también bajaron el $\mathrm{pH}$.

La germinación en cajas de petri severamente afectada por los extractos de las hojas u hojarasca de ambas especies. La germinación no se vio afectada en las macetas. En el primer año, e peso seco de los tallos fue menor que el testigo en tratamientos adicionados con eucaliptos. La reducción de peso fue mayor mientras naron. En el segundo año, el peso seco de los tallos se incrementó en las macetas que habian recibido hojas u hojarasca. Los suelos de plantación tuvieron más materia orgánica, $\mathrm{NH}_{4}-\mathrm{N}, \mathrm{P}$ y Ca que el suelo fuera de la plantación; éste último tuvo más altos niveles de $\mathrm{pH}, \mathrm{NO}_{3}-\mathrm{N}, \mathrm{Mg}$ y $\mathrm{K}$.

Los extractos de hojas inhibieron germinación y crecimiento de radícula in vitro, pero los lixiviados no. El crecimiento de las plántulas en maceta con hojarasca se redujo entre 11 y $17 \%$ aunque en el campo no se observó este efecto inhibitorio. plántulas.

Los extractos y lixiviados de hojas no fueron inhibitorios. Los lípidos foliares acumulados naturalmente en más hojas u hojarasca se adicio-

La hojarasca se aplicó en hileras después de la siembra . Las otras hojarascas provinieron de: Broussonatia papirifera Leucaena

leucocephala Pueraria hirsuta Shorea robusta

Los autores atribuyeron el bajo rendimiento del primer año a la inmovilización de nutrientes por microbios debido al bajo contenido de nitrógeno de las hojas comparado con su contenido de carbono.

Los autores sugieren que la alelopatía es de poca o nula importancia en el campo pues la competencia por agua mostró ser más importante que la de los nutrientes en la sobrevivencia y desempeño de las plántulas y brinzales. Trabajo realizado en Australia. el suelo fueron muy inhibidores in vitro y posiblemente también en pruebas con macetas suelo. Las plántulas en contacto con raíces de plantas viejas tuvieron una altura $90 \%$ menor que aquellas donde no se permitió el contacto de raíces viejas. Las macetas se mantuvieron bien regadas y fertilizadas. Las macetas regadas con lixiviados de raices viejas vivas fueron $50 \%$ menores que las re-
También se investigaron otros factores en la sobrevivencia de plántulas. La competencia por agua no resultó importante, pero los patógenos que potencialmente pueden causar muerte y bajo crecimiento en las plántulas. Los múltiples experimentos se diseñaron para explorar la importan del suelo mostraron 


\begin{tabular}{|c|c|c|c|c|c|}
\hline $\begin{array}{c}\text { Especie } \\
\text { Referencia }\end{array}$ & $\begin{array}{c}\text { Tipo de } \\
\text { experimento }\end{array}$ & $\begin{array}{c}\text { Especie } \\
\text { blanco }\end{array}$ & $\begin{array}{l}\text { Variable de } \\
\text { respuesta }\end{array}$ & Efecto & Comentarios \\
\hline
\end{tabular}

\begin{tabular}{|c|c|c|c|}
\hline & $\begin{array}{l}\text { regnans, lixiviados de } \\
\text { suelos con esas raíces } \\
\text { activas. }\end{array}$ & & \\
\hline $\begin{array}{l}\text { E. tereticornis } \\
\text { Suresh \& } \\
\text { Rai, } 1988 \\
\text { (R) }\end{array}$ & $\begin{array}{l}\text { Colectas y observa- } \\
\text { ciones de campo en } \\
\text { el sotobosque de } \\
\text { plantaciones unies- } \\
\text { pecíficas de E. tereti- } \\
\text { cornis, Casuarina } \\
\text { equisetifolia y Leu- } \\
\text { caena leucocephala } \\
\text { y de lugares vecinos } \\
\text { abiertos. }\end{array}$ & $\begin{array}{l}\text { Diversas } \\
\text { especies }\end{array}$ & $\begin{array}{l}\text { Riqueza de espe- } \\
\text { cies, biomasa } \\
\text { seca. }\end{array}$ \\
\hline $\begin{array}{l}\text { E. tereticornis } \\
\text { Singh \& } \\
\text { Kohli, } 1992\end{array}$ & $\begin{array}{l}\text { Experimento de } \\
\text { campo con cultivos } \\
\text { sembrados a diferen- } \\
\text { tes distancias de una } \\
\text { línea de árboles en } \\
\text { su lado sur. } \\
\text { Extracción de alelo- } \\
\text { químicos de los sue- } \\
\text { los (a varias distancias } \\
\text { de los eucaliptos) que } \\
\text { se usaron en bioen- } \\
\text { sayos en cajas petri. }\end{array}$ & $\begin{array}{l}\text { Brassica } \\
\text { oleracea } \\
\text { Brassica } \\
\text { campestris } \\
\text { Cicer arietinum } \\
\text { Lens esculentum } \\
\text { Trifolium } \\
\text { alexandrinum } \\
\text { Triticum } \\
\text { aestivum }\end{array}$ & $\begin{array}{l}\text { Rendimiento co- } \\
\text { mercial en expe- } \\
\text { rimento de campo. } \\
\text { Germinación en } \\
\text { bioensayo con } \\
\text { Lens esculentum. }\end{array}$ \\
\hline
\end{tabular}

\begin{tabular}{l|l} 
gadas con lixiviados de suelo de & cia de los diversos \\
bosque sin raíces; se controló fer- & factores, aunque no \\
tilización. Las raíces muertas re- & para detectar interac- \\
cién cortadas no produjeron & ciones entre ellos o \\
inhibición. El suelo acumulado en & para determinar cuál \\
la base de árboles grandes causó & era el más importan- \\
achaparramiento hasta por seis & te. Trabajo realizado \\
meses en los que liberó una so- & en Australia.
\end{tabular} lución rica en taninos. Después, las plántulas se desarrollaron normalmente.

Se encontraron 28 especies en lugares abiertos, 5 especies en el sotobosque de $L$. leucocephala, 12 bajo $E$. tereticornis y 18 bajo $C$. equisetifolia. La biomasa del sotobosque se redujo bajo todas las especies de árboles comparada a la de lugares abiertos, pero la mayor reducción ocurrió bajo $E$. tereticornis y la menor bajo $C$. equisetifolia.

Hubo reducción en rendimiento en todos los cultivos al menos hasta $7 \mathrm{~m}$ de distancia de los eucaliptos. El grado de reducción varió con la especie de cultivo. Lens esculentum fue el más afectado con reducción de rendimiento hasta $11 \mathrm{~m}$ de distancia de los eucaliptos. Los aleloquímicos estuvieron más concentrados cerca de los esculapios e inhibieron en bioensayo en esas concentracio-
Los autores atribuyeron los efectos diferenciales entre los árboles a alelopatía pues ellos midieron humedad, nutrientes del suelo y luz en las plantaciones y encontraron que eran similares bajo los árboles de las tres especies.

Los cultivos se regaron y fertilizaron de acuerdo con las prácticas agronómicas de la región de la India donde se hizo el experimento.

\section{Lileratura citada}

Alexander M.J. 1989. The long term effect of eucalyptus plantations on tin-mine spoil and its implication for reclamation. Landscape and Urban Planning 17:47-60.

Allolli T.B, Nalawadi U.G. and Sullikeri G.S. 1988. Influence of different forest tree species on yield and yield attributes of Coorg mandarin (Citrus reticulata Blanco) budded on two rootstocks under agroforestry system. Myforest 24:233-240. (Resumen)

Ashton D.H, Willis E.J. 1982. Antagonisms in the regeneration of Eucalyptus regnans in the mature forest. En: Newman E.I. Eds. The Plant Community as a Working Mechanism. British Ecological Society Special Publication, No. 1. Blackwell Scientific Publication, Oxford, 113-128.
Bansal G.L., Nayyar H. and Bedi Y.S. 1992. Allelopathic effect of Eucalyptus macrorhyncha and E. youmanii on seedling growth of wheat (Triticum aestitum) and radish (Raphanus sativus). Indian Journal of Agricultural Sciences 62:771-772.

Barton A.F.M., Tijandra J. and Nicholas P.G. 1989. Chemical evaluation of volatile oils in Eucalyptus species. Journal of Agricultural and Food Chemistry 37:1253-1257.

Basu P.K., Kapoor K.S., Nath S. and Banerjee S.K. 1987. Allelopathic influence: an assessment on the response of agricultural crops growing near Eucalyptus tereticornis. Indian Journal of Forestry 10:267-271. (Resumen).

Bhaskar V., Arali A. and Shankaralingappa B.C. 1992. Alleviation of allelopathic effects of eucalyptus hybrid trough litter burning. En: Tauro P. Narwal S.S. Eds. First National Symposium. Allelopathy in agroecosystems. Feb. 12-14. Hi- 
sar, India; Indian Society of Allelopathy, CCS Haryana Agricultural University, 118-119. (Resumen).

Bowman D.M.J.S. and Kirkpatrick J.B. 1986. Establishment, suppression and growth of Eucalyptus delegatensis R.T. Baker in multiaged forests. III. Intraspecific allelopathy, competition between adult and juvenile for moisture and nutrients, and frost damage to seedlings. Australian Journal of Botany 34:81-94.

Bruna E.D. Fernandes B. Borges A.C. Almeida-Filho J. de, Barros N.F. de, De Almeida-Filho R. and De Barros N.F. 1989. Effects of Eucalyptus litter extracts on microbial growth. Pesquisa Agropecuaria Brasileira 24:1523-1528. (Resumen).

Dalal M.R., Dahiya D.S., Sarmah M.K., and Narwal S.S. 1992. Suppresion effects of arid-zone trees on plant stand and growth of crops. En: Tauro P, Narwal SS, edrs. First National Symposium. Allelopathy in agroecosystems. Feb. 1214. Hisar, India; Indian Society of Allelopathy, CCS Haryana Agricultural University, 132-135. (Resumen).

Del Moral R. and Müller C.H. 1969. Fog drip: a mechanism of toxic transport from Eucalyptus globulus. Bulletin of the Torrey Botanical Club 96:467-475.

Del Moral R. and Müller C.H. 1970. The allelopathic effects of Eucalyptus camaldulensis. American Midland Naturalist 83:254-282.

Del Moral R., Willis R.J. and Ashton D.H. 1978. (Allelopathic) Suppression of coastal heath vegetation by Eucalyptus baxteri (in Victoria). Australian Journal of Botany 26:203219.

Domínguez M.T., Esparcia E.G. and Peñalva F. 1988. Effect on seed germination of the water soluble extract of leaves of introduced (Eucalyptus globulus) and native Mediterranean species (Quercus suber, Q. ilex, Pinus pinea, Cistus ladanifer and Halimium halimifolium). Anales de Edafología y Agrobiología 47:948-953. (Resumen).

Gehrke P.C. Revell M.B. and Philbey A.W. 1993. Effects of river red gum, Eucalyptus camaldulensis, litter on golden perch, Macquaria ambigua. Journal of Fish Biology 43:265-279

Gosh S.P., Nair G.M., Pillai N.G., Ramanujam T, Mohankumar B. and Lakshmi K.R. 1987. Growth, productivity and nutrient uptake by cassava in association with four perennial species. Tropical Agriculture 64:233-236.

Gosh S.P., Kumar B.M., Kabeerathumma S. and Nair G.M. 1989. Productivity, soil fertility and soil erosion under cassava based agroforestry systems. Agroforestry Systems 8:67-82.

Harper J.L. 1977. The Population biology of plants. Academic Press, London. pp. 369-381.

Herms D.A. and Mattson W.J. 1992. The dilemma of plants: to grow or defend. The Quarterly Review of Biology 67:283335.

Hillis W.E. 1966. Polyphenols in the leaves of Eucalyptus L'Herit: a chemotaxonomic survey. I. Introduction and study of the series Globulares. Phytochemistry 5:1075-1090.
Hillis W.E. 1967. Polyphenols in the leaves of Eucalyptus L'Herit: a chemotaxonomic survey. II. The sections Renantheroidae and Rhenantherae. Phytochemistry 6:259-274.

Igboanugo A.B.I. 1988a. Morphology and yield of chili (Capsicum annum) in relation to distance from lemon-scented eucalyptus (Eucalyptus citridora) stands. Indian Journal of Agricultural Sciences 58:317-319.

Igboanugo A.B.I. 1988b. Effects of some eucalypts on yields of Vigna unguiculata L. Walp., Zea mays L. and Sorghum bicolor L. Agriculture, Ecosystems and Environment 24:453-458.

Jonsson K., Fidjeland L., Maghembe J.A. and Högberg P. 1988. The vertical distribution of fine roots of five tree species and maize in Mogoro, Tanzania. Agroforestry Systems 6:63-69.

Joshi P.C., Om-Prakash, Prakash O. 1992. Allelopathic effects of litter extract of some tree species on germination and seedling growth of agricultural crops. En: Tauro P. and Narwal S.S., Eds. First National Symposium. Allelopathy in agroecosystems. Feb. 12-14. Hisar, India; Indian Society of Allelopathy, CCS Haryana Agricultural University, 127128. (Resumen).

Kamal Sharma, Sharma I.M. and Sharma N.K. 1995. Preliminary studies on the effect of wind breaks on growth and yield of mango (Mangifera indica L. cv. ) Indian Forester 121:122-125. (Resumen)

Kohli R.K., Singh D. and Verma R.C. 1990. Influence of eucalypt shelterbelt on winter season agroecosystems. Agriculture Ecosystems and Environment 33:23-31.

Kohli R.K. and Singh, D. 1991. Allelopathic impact of volatile from Eucalyptus on crop plants. Biologia Plantarum (Prague) 33:475-483.

Kokumai M., Konoshima T. and Kozuka M. 1991. Euglobal T1, a new euglobal from Eucalyptus tereticornis. Journal of Natural Products 54:1082-1086.

Konar J. and Kushari D.P. 1989. Effect of leaf leachate of four species on sprouting behavior of rhizomes, seedling growth and diosgenin content of Costus speciosus. Bulletin of the Torrey Botanical Chub 116:339-343.

Konar J. and Kushari D.P. 1995. Effect of Eucalyptus globulus leachates on the growth and diosgenin content of Costus speciosus. Allelopathy Journal 2:215-218.

Lima W.P. 1987. Impacto ambiental del Eucalipto. Desarrollo Forestal Ed., Tabasco, México.

Lisanework N, Michelsen A. 1993. Allelopathy in agroforestry systems: The effects of leaf extracts of Cupressus lusitanica and three Eucalyptus ssp. on four Ethiopian crops. Agroforestry Systems 21:63-74.

Martínez-Gómez M.E., Guerra-Hernández E. and MontillaGómez J.Y. 1993. Physicochemical analysis of Spanish commercial Eucalyptus honeys. Journal of Apiculture Research 32:121-126.

May F.E. and Ash J.E. 1990. An assessment of the allelopathic potential of Euicalyptus. Australian Journal of Botany 38:245-254. 
Molina R., Reigosa M.J. and Carballeira R. 1991. Release of allelochemical agents from litter, throughfall, and topsoil in plantations of Eucalyptus globulus Labill in Spain. Journal of Chemical Ecology 17:147-160.

Nandal D.P.S., Bisla S.S. and Narwal S.S. 1992. Allelopathic influence of eucalyptus and polar aqueous leaf extracts on the germination and seedling growth of winter vegetables. En: Tauro P. and Narwal S.S, Eds. First $\mathrm{Na}$ tional Symposium. Allelopathy in agroecosystems. Feb. 12-14. Hisar, India; Indian Society of Allelopathy, CCS Haryana Agricultural University, 98-100. (Resumen).

Nishimura H., Nakamura T. and Mizutani J. 1984. Allelopathic effects of p-menthane-3-8-diols in Eucalyptus citriodora. Phytochemistry 23:2777-2779.

Okamura H., Mimura A., Yakou Y., Niwano M. and Takahara Y. 1993. Antioxidant activity of tanins and flavonoids in Eucalyptus rostrata. Phytochemistry 33:557-561.

Onyewotu L.O.Z. and Stigter C.J. 1.995. Eucalyptus- its reputation and its roots: millet and a Eucalyptus shelterbelt in northern Nigeria. Agroforestry Today 7:6-8.

Onyewotu L.O.Z., Ogigirigi M.A. and Stigter C.J. 1994. A study of competitive effects between a Eucalyptus camaldulensis shelterbelt and an adjacent millet (Pennisetum typhoides) crop. Agriculture, Ecosystems and Environment 51:281-286.

Paulino V.T., Sánchez M.J.F, and Werner J.C, Goncalvez MAZ. 1987. Allelopathic effect of Eucalyptus on forage growth. Revista de Agricultura Piracicaba 62:17-35.

Poore M.D. and Fries C. 1505. Tho Ecological effects of eucalyptus. FAO Forestry Paper 59.

Pryor L.D. 1976. The Biology of Eucalyptus. Edward Arnold Ltd. London.

Rai R.S.V. and Suresh K.K. 1988. Agrosilvicultural studies -optimum species combination. International Tree Crops Journal 5:1-8.

Rajashekhara E., Sreenivasa M.N. and Bhat R.S. 1989. Effect of cropping system on vesicular-arbuscular mycorrhizal development in redgram and sunflower. Karnataka Journal of Agricultural Sciences 2:231-233.

Rice E.L. 1984. Allelopathy. 2nd. Ed, Academic Press, Orlando, Florida.

Sanginga N. and Swift M.J. 1992. Nutritional effects of Eucalyptus litter on the growth of maize (Zea mays). Agriculture Ecosystems and Environment 41:55-65.

Sanker K.B. and Rai R.S.V. 1993. Allelopathic effects of a few tropical hardwoods on olericultural crops. Indian Journal of Forestry 16:246-249. (Resumen).
Sharma K., Dhillon M.S. and Dhingra K.K. 1987. Presence of germination inhibitors in the leaf leachates of some farm grown trees. Indian Forester 113 816-820. (Resumen)

Shivanna L.R. and Prasanna K.T. 1992. Allelopathic effects of Eucalyptus: an assessment on the response of agricultural crops. Myforest 28:131-137. (Resumen).

Shrivastava M.B. and Lal C.B. 1989. Biomass plantation and farm forestry: choice of Eucalyptus species: enviromentalists versus foresters. Indian Journal of Forestry 12:247-254.

Sidhu D.S. and Hans A.S. 1988. Preliminary studies on the effect of Eucalyptus leaf-litter on accumulation of biomass in wheat. Journal of Tropical Forestry 4:328-333.

Singh D., Kohli R.K. and Saxena D.B. 1991. Effect of eucalyptus oil on germination and growth of Phaseolus aureus Roxb. Plant and Soil 137: 223-228.

Singh D. and Kohli R.K. 1992. Impact of Eucalyptus tereticornis Sm. shelterbelts on crops. Agroforestry Systems 20:253266.

Souto X.C., González L. and Reigosa M.J. 1994. Comparative analysis of allelopathic effects produced by four forestry species during decomposition process in their soils in Galicia. Journal of Chemical Ecology 20:3005-3015.

Souto X.C., González L. and Reigosa M.J. 1995. Allelopathy in forest environment in Galicia, NW Spain. Allelopathy Journal 2:67-78.

Suresh K.K. and Rai R.S.V. 1987. Studies on the allelopathic effects of some agroforestry tree crops. International Tree Crops Journal 4:109-115. (Resumen).

Suresh K.K.nd Rai R.S.V. 1988. Allelopathic exclusion of understory by a few multipurpose trees. International Tree Crops Journal 5:3, 143-151. (Resumen).

Toky O.P. and Singh V. 1993. Litter dynamics in short-rotation high density tree plantations in an arid region of India. Agriculture Ecosystems and Environment 45:129-145

Tomar V.P.S., Narain P. and Dadhwal K.S. 1992. Effect of perennial mulches on moisture conservation and soilbuilding properties through agroforestry. Agroforestry Systems 19:241-252.

Whitehead D.C., Dibb H., and Hartley R.D. 1983. Bound phenolic compounds in water extracts of soils, plant roots and leaf litter. Soil Biology and Biochemistry 15:133-136.

Wilt F.M., Miller G.C. and Everett R.L. 1993. Measurement of monoterpene hydrocarbon levels in vapor phase surrounding single leaf pinyon (Pinus monophylla Torr. and Frem.: Pinaceae) understory litter. Journal of Chemical Ecology 19:1417-1428. 